\title{
Ordered Mesoporous to Macroporous Oxides with Tunable Isomorphic Architectures - Solution Criteria for Persistent Micelle Templates
}

\author{
Hasala N. Lokupitiya ${ }^{1}$, Alexis Jones ${ }^{1}$, Barry Reid ${ }^{2}$, Stefan Guldin², Morgan Stefik ${ }^{1 *}$ \\ ${ }^{1}$ Department of Chemistry and Biochemistry, University of South Carolina, Columbia, South Carolina 29208, \\ United \\ States; \\ ${ }^{2}$ Department of Chemical Engineering, University College London, Torrington Place, London, WC1E 7JE, United \\ Kingdom
}

KEYWORDS: Structure-directing agents; Poly(ethylene oxide- $b$-hexyl acrylate); FloryHuggins effective interaction parameter; Macroporous; Mesoporous; Persistent micelle template (PMT); Block copolymer coassembly; Transition metal oxides.

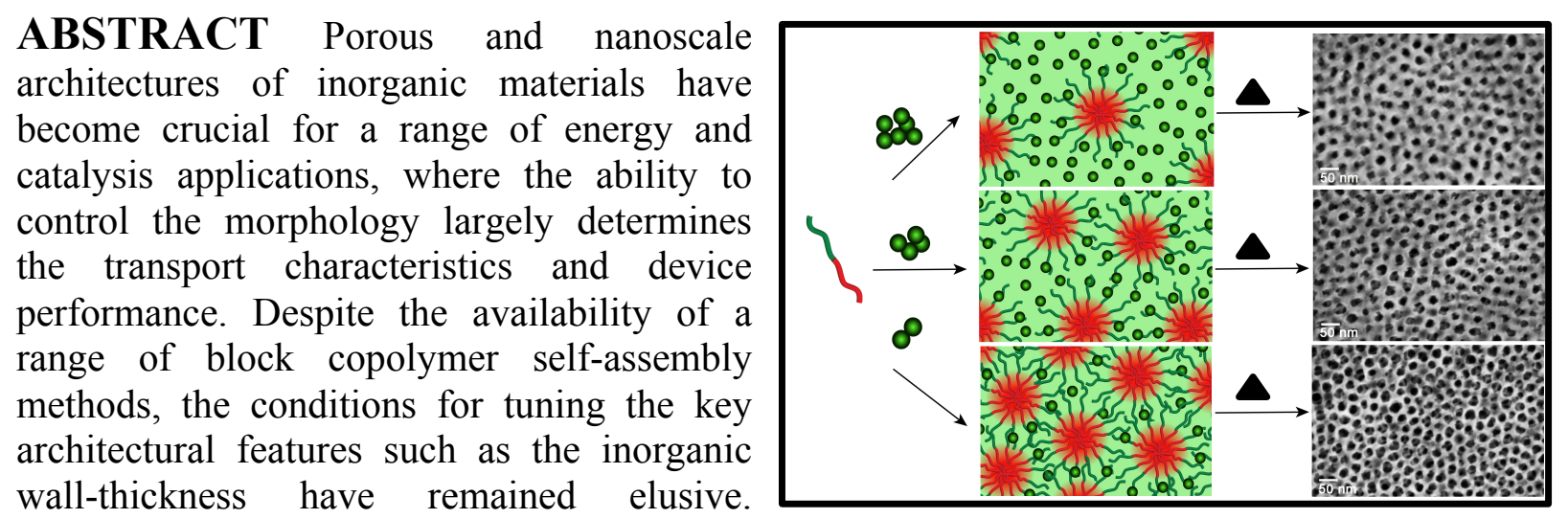

Towards this end we have developed solution processing guidelines that enable isomorphic nanostructures with tunable wall-thickness. A new poly(ethylene oxide- $b$-hexyl acrylate) (PEO$b$-PHA) structure directing agent (SDA) was used to demonstrate the key solution design criteria. Specifically, the use of a polymer with a high Flory-Huggins effective interaction parameter, $\chi$, and appropriate solution conditions leads to the kinetic entrapment of persistent micelle templates (PMT) for tunable isomorphic architectures. Solubility parameters are used to predict conditions for maintaining persistent micelle sizes despite changing equilibrium conditions. Here the use of different inorganic loadings controls the inorganic wall-thickness with constant pore size. This versatile method enabled a record $55 \mathrm{~nm}$ oxide wall-thickness from micelle coassembly as well as the seamless transition from mesoporous materials to macroporous materials by varying the polymer molar mass and solution conditions. The processing guidelines are generalizable and were elaborated with three inorganic systems, including $\mathrm{Nb}_{2} \mathrm{O}_{5}, \mathrm{WO}_{3}$, and $\mathrm{SiO}_{2}$ that were thermally stable to $600{ }^{\circ} \mathrm{C}$ for access to crystalline materials. 


\section{INTODUCTION}

Crystalline transition metal oxides with nanoscale porous structures are in high demand for energy and catalytic applications that take advantage of their high surface area and interconnected structures. For example, electrochemical devices such as dye sensitized solar cells, mesoscopic perovskite solar cells, batteries, supercapacitors, fuel cells, and photoelectrochemical devices for solar fuels all take advantage of access to crystalline metal oxides with interconnected mesopores. ${ }^{1-25}$ The improvement of such devices relies upon judicious optimization of the nanoscale morphology to match the transport limitations of the inorganic materials. Furthermore, many device designs rely on subsequent material deposition $^{6,26-29}$ by atomic layer deposition or electrodeposition, for example, and will benefit from architectures that are continuously variable beyond the typical $10-30 \mathrm{~nm}$ feature sizes from block copolymers up towards larger $100 \mathrm{~nm}$ feature sizes more commonly found from colloidal template techniques. ${ }^{30-33}$ Please note the use of IUPAC poresize naming convention for $2-50 \mathrm{~nm}$ mesopores and $>50 \mathrm{~nm}$ macropores. ${ }^{34,}{ }^{35}$ The extension of block copolymer coassembly continuously from the mesoporous regime into the macroporous regime opens up new opportunities for ideal comparative studies that use a single synthesis method. In particular, the inorganic wall-thickness plays a crucial role on device performance where both ion diffusion into the electrode and electron transport along the electrode depend on morphology. ${ }^{36}$ Additionally, the wall-thickness affects the overall mass of active material in a given volume and thus influences the energy density of energy storage devices.

Structure directing agents (SDA) enable the evaporation induced coassembly of nanostructured inorganic materials. The field has continuously evolved over the past two decades where typical SDAs are amphiphilic molecules having a hydrophilic portion and a hydrophobic portion covalently bound together. Generally, the hydrophilic portion selectively interacts with hydrophilic inorganic species via electrostatic or hydrogen bonding while the hydrophobic portion phase separates with nanoscale periodicity.
Surfactant molecules were the first used SDAs ${ }^{37}$ where the nominal pore diameter was initially restricted to $1-5 \mathrm{~nm}$ and was later expanded with swelling agents. ${ }^{38,} 39$ The introduction of amphiphilic block copolymer SDAs with significantly higher molar mass expanded the accessible mesopore sizes to $5-30 \mathrm{~nm}^{40,41}$ Here, the resulting structural dimensions are dictated by the polymer chain dimensions and is conceptually distinct from vesicle templating. ${ }^{42-44}$ A range of BCP SDAs have been elaborated including poly(ethylene oxide- $b$-propylene oxide- $b$-ethylene oxide $)^{41,}{ }^{45}$, poly(isoprene- $b$-ethylene oxide), ${ }^{40}$ poly(styrene- $b$-ethylene oxide), ${ }^{46-49}$ poly(ethylene oxide- $b$-acrylonitrile), ${ }^{50,} \quad{ }^{51} \quad$ poly(methyl methacrylate- $b$-ethylene poly(isobutylene- $b$-ethylene oxide), ${ }^{52-54}$ poly(ethylene-alt-propylene- $b$-ethylene oxide) ${ }^{61}$, poly(isoprene- $b$-styrene- $b$-ethylene oxide), ${ }^{62-64}$ for nanostructured silicates and transition metal oxides.

Access to continuously tunable isomorphic architectures is crucial in establishing propertyperformance relationship for novel nanostructured materials. A predictive self-assembly methodology is needed to provide for such nuanced structural control. The approaches used with the numerous BCP SDAs mentioned above, resulted in either mesoporous materials alone or macroporous materials from vesicles where neither strategy has yet enabled continuous tuning of pore sizes across these regimes. ${ }^{42-44,52,}{ }^{65}$ Furthermore adjusting the amount of inorganic material in equilibrating systems results in significant morphology changes with different symmetry and changing connectivity ${ }^{66}$ that alone may lead to performance changes. Coassembly with non-dynamic micelles ${ }^{67}$ is expected over limited experimental conditions where predictive processing guidelines are needed to enable widespread development. Systematic investigations into length scale dependent properties would ideally be conducted with an isomorphic approach that has capabilities spanning the gamut from mesopores to macropores.

Herein, we present BCP solution processing guidelines that enable tunable isomorphic architectures with adjustable inorganic wallthickness. This approach enables concomitant 
access to extensive pore size regimes that seamlessly span from mesopores to macropores. This concept is demonstrated with a new PEO- $b$ PHA SDA. The use of a polymer with sufficiently high Flory-Huggins interaction parameter is needed to inhibit micelle re-equilibration that would otherwise change the final pore size with different inorganic loadings. Both micelle fusion-fission and unimer expulsion-insertion reactions may be slowed with appropriate solution conditions that inhibit micelle changes. ${ }^{68-72}$ The demonstrated broad range of tunable pore sizes fills the gap typically found between block copolymer approaches and colloidal approaches. The resulting materials were stable to high temperatures and enabled the formation of multiple crystalline oxide frameworks.

\section{Experimental Methods}

Reagents: Anhydrous, inhibitor free THF ( $>99.9 \%$, Aldrich), Niobium (V) ethoxide (99.9\%, Fisher) and Tungsten (VI) chloride (99.9\%, Acros) were stored inside a glove box and used as received. Concentrated hydrochloric acid (37 wt $\%$ ACS grade, VWR) and Tetraethoxysilane (98\%, Alfa Aesar) were used as received. Poly(ethylene glycol) methyl ether $\left(\mathrm{M}_{\mathrm{n}}\right.$ 20, $000 \mathrm{~g} \mathrm{~mol}^{-1}$, Aldrich) was dried by azeotropic distillation with toluene before use.

PEO-Br Macroinitiator Synthesis: PEO-Br was prepared by an esterification procedure. In a typical experiment, $10 \mathrm{~g}$ of PEO-OH was dissolved in 33 $\mathrm{mL}$ methanol free methylene chloride, and 0.054 $\mathrm{mL}$ of 2-bromopropionic acid was added with nitrogen flow at RT. Then the mixture was cooled to $0{ }^{\circ} \mathrm{C}$ before the addition of $0.0244 \mathrm{~g}$ of 4 (dimethylamino)pyridine and $0.1238 \mathrm{~g}$ of $\mathrm{N}, \mathrm{N}^{\prime}-$ dicyclohexylcarbodiimide (PEO: 2-bromopropionic acid: 4-(dimethylamino)pyridine: $\quad \mathrm{N}, \mathrm{N}^{\prime}$ dicyclohexylcarbodiimide $=1: 1 \cdot 2: 0.4: 1.2)$. The reaction was stirred overnight at room temperature. The precipitated dicyclohexylurea was removed by filtration and then the methylene chloride was removed by vacuum. The product was next dissolved in THF and precipitated three into cold diethyl ether (THF:diethyl ether=1:15). The precipitated product was filtered and washed thoroughly with the same solvent and dried at $40{ }^{\circ} \mathrm{C}$ for $24 \mathrm{~h}$ inside a vacuum oven. The quantitative reaction of the hydroxyl group of the poly(ethylene glycol)methyl ether was determined by ${ }^{1} \mathrm{H}$ NMR spectroscopy (S1).

PEO-b-PHA Diblock Copolymer Synthesis: The monomer hexyl acrylate was passed through a basic alumina column just prior to use. The poly(hexyl acrylate) block was prepared by atom transfer radical polymerization as follows. First $0.75 \mathrm{~g}$ of PEO-Br macroinitiator was dissolved in $0.85 \mathrm{~mL}$ of DMF inside a schlenk flask and stirred until it dissolved. Moderate heat of $\sim 40{ }^{\circ} \mathrm{C}$ was used to promote dissolution. Then $4.26 \mathrm{~mL}$ of hexyl acrylate and $10.4 \mu \mathrm{L}$ of HMTETA were added to the above mixture. After $10 \mathrm{~min}$ of stirring, the solution was subjected to three freeze-pump-thaw (FPT) cycles. At last step, the flask was kept frozen and $5.4 \mathrm{mg}$ of $\mathrm{Cu}(\mathrm{I}) \mathrm{Br}$ was added under flowing nitrogen. Then the flask was sealed under flowing nitrogen and another FPT cycle was carried out. The flask was subsequently kept at room temperature until the mixture was thawed. Then it was kept in a preheated oil bath at $70{ }^{\circ} \mathrm{C}$ with constant stirring. After $17.5 \mathrm{~h}$ the polymerization was stopped by cooling the reaction mixture with ice water before exposing the catalyst to air. The crude polymerization solution was diluted with THF and the solution was passed through a basic alumina column to remove $\mathrm{CuBr}$. The filtrate was concentrated via vacuum and precipitated two times into cold methanol $\left(-78{ }^{\circ} \mathrm{C}\right)$. The product was filtered and vacuum dried at $40{ }^{\circ} \mathrm{C}$ for $24 \mathrm{~h}$. The molar mass of PHA was determined by ${ }^{1} \mathrm{H}$ NMR relative to the $\mathrm{PEO}$ macroinitiator and gel permeation chromatography (GPC) was used to obtain the molar mass dispersity. (Figure S2)

\section{Synthesis of Different Mesoporous Metal Oxides Thin Films}

$\mathrm{Nb}_{2} \mathrm{O}_{\mathbf{5}}$ Wall Thickness Tuning: PEO- $b$-PHA (22.4 $\mathrm{mg}$ ) block copolymer was dissolved in $2.0 \mathrm{~mL}$ of anhydrous inhibitor free THF with continuous stirring for $1 \mathrm{~h}$. The polymer solution was heated up to $40{ }^{\circ} \mathrm{C}$ at the beginning to completely dissolve the polymer. Then $100 \mu \mathrm{L}$ of $37 \% \mathrm{w} / \mathrm{w}$ conc: $\mathrm{HCl}$ was added very slowly to the polymer solution while 
stirring. The solution was subsequently vortexed for $5 \mathrm{~min}$ at $2000 \mathrm{rpm}$ followed by the desired amount of niobium ethoxide as tabulated in Table III. Sample P3-2.4to3.0- $\mathbf{N b}_{2} \mathrm{O}_{5}$ was similarly prepared P3-2.4- $\mathrm{Nb}_{2} \mathrm{O}_{5}$ but had additional acid was added after adjusting the I:O ratio to 2.4. Subsequently, 26 $\mu \mathrm{l}$ of additional niobium ethoxide was added to increase the $\mathrm{I}: \mathrm{O}$ ratio to 3.0 . The resulting solutions were slowly shaken for $1 \mathrm{~h}$ before casting. The solution was dip coated onto plasma cleaned 0.25 $\mathrm{mm} \times 0.8 \mathrm{~mm}$ silicon wafer at a $4.4 \mathrm{mms}^{-1}$ constant withdrawal rate inside a $20-25 \%$ humidity chamber at $25{ }^{\circ} \mathrm{C}$. The humidity chamber used in this study was home-made with adjustable purge gas to regulate humidity. Water saturated air was achieved by passing dry air through a submerged aquarium stone. The purge gas humidity was adjusted by the ratio of dry air to humid air, and monitored by a hygrometer. The resulting thin films were placed on a hot plate at $60{ }^{\circ} \mathrm{C}$ for $2 \mathrm{~h}$ and heated to $100{ }^{\circ} \mathrm{C}$ for overnight to promote condensation. The plasma cleaner used in this study was Fisher model 1020 and the plasma was generated with a mixture of 24.6\% $\mathrm{O}_{2}$ balanced Ar. Finally the samples were calcined in air with $10{ }^{\circ} \mathrm{C} / \mathrm{min}$ ramp and $1 \mathrm{~min}$ hold at $600{ }^{\circ} \mathrm{C}$ followed by natural cooling.

WO$_{3}$ : PEO- $b$-PHA (50 mg) block copolymer was dissolved in $2.8 \mathrm{~mL}$ of anhydrous inhibitor free THF with continuous stirring for $1 \mathrm{~h}$. The polymer solution was heated up to $40{ }^{\circ} \mathrm{C}$ at the beginning to completely dissolve the polymer. Then $0.125 \mathrm{ml}$ of $37 \% \mathrm{w} / \mathrm{w}$ conc: hydrochloric acid was added very slowly to the polymer solution under continuous stirring. The solution was stirred for $1 \mathrm{~h}$ before 0.13 $\mathrm{g}$ of $\mathrm{WCl}_{6}$ was added to the solution. Then the same dipping, aging, and calcining procedures described above were used. $\mathbf{S i O}_{2}$ : PEO- $b$-PHA (100 mg) block copolymer was dissolved in $1.54 \mathrm{~mL}$ of anhydrous inhibitor free THF. In a separate vial, $0.252 \mathrm{~g}$ of tetraethyl orthosilicate (TEOS), $0.12 \mathrm{~g}$ of $0.5 \mathrm{M} \mathrm{HCl}$ and $0.847 \mathrm{ml}$ of anhydrous inhibitor free THF were mixed together. These two solutions were continuously stirred for $1 \mathrm{~h}$ at $60{ }^{\circ} \mathrm{C}$ and cooled to room temperature before combining the two solutions. The combined solution was then stirred for $2 \mathrm{~h}$ at room temperature before dip coating, aging, and calcining was carried out as described above.

\section{Characterization}

FE-SEM: Morphologies of the mesoporous thin films were observed with a Zeiss Ultraplus thermal field emission SEM using an acceleration voltage of $5 \mathrm{keV}$ and an in-lens secondary electron detector. The working distance was kept to $3.00 \mathrm{~mm}$ or less during the acquisition of the images. Amorphous samples were plasma cleaned prior to imaging and calcined samples were imaged directly. In both cases $\mathrm{Cu}$ strips were used to improve electrical contact to the sample.

GISAXS and GIWAXS: X-ray scattering experiments were conducted using a SAXSLab Ganesha at the South Carolina SAXS Collaborative. A Xenocs GeniX3D microfocus source was used with a $\mathrm{Cu}$ target to generate a monochromic beam with a $0.154 \mathrm{~nm}$ wavelength. The instrument was calibrated using a silver behenate reference with the first order scattering vector $q^{*}=1.076 \mathrm{~nm}^{-1}$, where $q=4 \pi \lambda^{-1} \sin \theta$ with a total scattering angle of $2 \theta$. A Pilatus $300 \mathrm{~K}$ detector (Dectris) was used to collect the two-dimensional (2D) scattering patterns. Radial integration of 2D WAXS patterns reduced the data to 1D profiles using SAXS GUI software. GISAXS and GIWAXS experiments were conducted with an incident angle near $0.22^{\circ}$, and the samples were rotated relative to the incident beam as shown in Figure S6. The sample-to-detector distance of 1050 $\mathrm{mm}$ was used for GISAXS whereas $104.5 \mathrm{~mm}$ was used for GIWAXS. The in-plane $\mathrm{q}_{\mathrm{y}}$ data were processed using Matlab scripts and equation 4. $\chi$ Measurements Using Temperature Controlled Stage: The bulk morphology of the polymers were obtained at different temperatures using a Linkam Scientific Instruments HFS350X-GI hot stage. For each experiment, the background scattering from the particular pair of mica sheets used to fix the sample was measured before loading polymer. Polymers were dissolved in THF and filtered through $0.2 \mu \mathrm{m}$ filter and dried prior to use. The melted polymer $\left(40-50{ }^{\circ} \mathrm{C}\right)$ was placed on a mica sheet (thickness of mica $\sim 20 \mu \mathrm{m}, 34 \%$ X-ray transmission from Molmex Scientific Inc) with a rubber $\mathrm{O}$ ring and the next sheet of mica was placed slowly without trapping any air inside the sandwich. 
The prepared sandwich cell loosely clamped and placed in a vacuum oven for few minutes before sealing and mounting on the Linkam stage. All data acquired for bulk polymer studies were equilibrated for 1 hour and then measured for 1 hour at the desired temperatures with an incident X-ray flux of $\sim 1.5 \mathrm{M}$ photons per second on the sample. Matrixassisted laser desorption ionization time-of-flight MALDI-TOF spectroscopy was used to accurately measure the $\mathrm{Mn}$ of the commercial PEO homopolymers. Bruker Ultraflex MALDITOF/TOF instrument was used to collect the data nitrogen laser source operating at a wavelength of $337 \mathrm{~nm}$ and a pulse rate of $3-5 \mathrm{~Hz}$. The matrix used for the experiment was $\alpha$-cyano-4-hydroxycinnamic acid. The number average molar mass was calculated for each sample used for thermodynamic measurements. Each scattering curve was background subtracted to remove the minimal contributions from the mica sample holders. The data was fitted using Matlab to convolve the Leibler random phase approximation ${ }^{73}$ with a Gaussian instrumental point spread function. A common reference lattice volume of $0.118 \mathrm{~nm}^{3}$ was used to determine the number of lattice sites occupied by each polymer at each temperature based upon temperature dependent density data. Similarly, the volume fractions were calculated at each temperature using the same density data. The instrumental broadening was measured as follows. The beam configuration was adjusted such that the total flux was within the linear intensity regime of the Pilatus detector ( $\sim 1 \mathrm{M}$ photons/second) and a direct image of the beam was fitted well with a Gaussian profile. An arbitrary silver behenate sample (TCI America) was measured with the same configuration to determine the peak width associated with the sample alone. The same sample was then measured with other brighter beam configurations used on the polymer samples. The different observed widths of the first silver behenate peak were used to calculate the instrumental broadening factors under particular configurations. The polymer SAXS data were collected with a beam configuration corresponding to Gaussian point spread function with a full-width half-max (FWHM) $0.0269 \mathrm{~nm}^{-1}$. This minor correction had little effect on the interpreted $\chi$ parameters. Transmission WAXS for Crystallite Size
Analysis: Identical thin-film samples were prepared on mica substrates for measurements with a transmission geometry to minimize geometric smearing. The instrumental broadening factor was measured with a WAXS configuration using NIST reference material 640c. The instrumental broadening factor was fit as a Gaussian point spread function with a FWHM $0.0128 \mathrm{~nm}^{-1}$ that smeared the NIST instrument-independent FWHM to the FWHM value measured with our WAXS configuration. The same Gaussian point spread function was taken into account to interpret scattering data as a combination of grain-size broadening per the Scherrer formula with the same Gaussian point spread function.

\section{PHA Temperature Dependent Density} Measurement: The density of PHA was determined using water displacement with a pycnometer at different temperatures. Initially liquid PHA was placed in a pre-weighed pycnometer and the mass of PHA was recorded. Then the container was filled with deionized, degassed water and the entire setup was equilibrated at the desired temperature. After equilibration, a capillary stopper was promptly added to displace the excess water and yield a reproducible total system volume. The volume of water was calculated using tabulated temperature dependent density values and subtracted from baseline measurements to determine the volume of PHA at each temperature. The temperature dependency of the PHA density was found as $\rho_{\mathrm{PHA}}=-0.0008 \mathrm{~T}+$ 1.064, where $\rho$ is the density in $\mathrm{g} / \mathrm{mL}$ and $\mathrm{T}$ is temperature in Celsius. These values were confirmed with a secondary measurement of PHA using Helium pycnometer (AccuPyc II 1340) at fixed temperature and gave a similar value of 1.065 $\pm 0.004 \mathrm{~g} \mathrm{~cm}^{-3}$ at $22{ }^{\circ} \mathrm{C}$. Estimation of Solubility Parameters:The group contribution method was used to calculate the Hildebrand parameter of hexyl acrylate based on the enthalpy of evaporation of each group. The volume fractions of each component in the solution mixture were used to calculate the Hildebrand parameters of the different solvent mixtures by assuming each component occupies a volume corresponding to their pure densities. Here values of 18.6, 47.9, and 26 were used for THF, water, and ethanol, respectively. ${ }^{74}$ 
Derivation of the Relationship between Wall Thickness to I:O Ratio: The relationship between wall-thickness in the (100) plane and I:O ratio was derived by considering a BCC micelle model that only considered the micelle core size and the ratio of inorganic content to organic content. The volume occupied by the PEO chains within the inorganic was not taken in to account. The density of the amorphous niobia sol was a fit parameter determined using a least-squares optimization. The calculated density for amorphous niobia was 1.88 $\mathrm{g} / \mathrm{cm}^{3}$, which is in agreement with prior work that found amorphous sol to have less than half the density of the parent crystalline solids. ${ }^{45,75}$ GPC: Molecular weights and molar mass dispersities were measured using a Polymer Labs PL-GPC-120 GPC with a 515 HPLC pump, a 2410 refractive index detector, and three Styragel columns. The columns consisted of HR1, HR3 and HR4 which have the corresponding effective molecular weight ranges of 100-5000 $\mathrm{g} \mathrm{mol}^{-1}, 500-30000 \mathrm{~g} \mathrm{~mol}^{-1}$, and 5000$500000 \mathrm{~g} \mathrm{~mol}^{-1}$, respectively. THF was used as the eluent at a temperature of $30^{\circ} \mathrm{C}$ and a flow rate of $1.0 \mathrm{~mL} \mathrm{m^{-1 }}$ with the calibration of polystyrene standards obtained from Polymer Laboratories. GPC samples were prepared by dissolving the sample in THF at a concentration of $2.0 \mathrm{mg} / \mathrm{mL}$ and passing through micro filters with average pore size of $0.2 \mu \mathrm{m}$.

\section{Ellipsometry Prosimetry: Ellipsometric} Porosimetry (EP) was carried out on a spectroscopic ellipsometer (Semilabs SE-2000) coupled with an Atmospheric Ellipso-Porosimetry module using water as sorbent and nitrogen as carrier gas. The sample was placed in a chamber in which the humidity was controlled by two mass flow controllers that regulate the flow of saturated and dry gas. The ellipsometry measurements were carried out at room temperature at an angle of 73 degrees, corresponding to the approximate Brewster angle of the silicon substrate. Data analysis was then carried out with the software of the instrument (Semilabs Spectroscopic Ellipsometry Analyser). A Tauc-Lorentz dispersion law was applied to the data to obtain values of the refractive index at each humidity point, corresponding to the adsorption of water molecules into the pores. ${ }^{76}$ The adsorptiondesorption isotherm then allowed to derive both, the relative adsorbed solvent volume and corresponding absolute porosity ${ }^{77}$ as well as a pore radius distribution $^{78}$ via an effective medium approximation and a modified Kelvin formula, respectively.

Contact angle measurements: A VCA Optima (AST Products, Inc) instrument was used to measure the contact angle with a manual controller capable of casting $2 \mu \mathrm{l}$ of Milli-Q water droplets. Before taking the measurements, the films were dried using a flow of $\mathrm{N}_{2}$ for 30 seconds. Static contact angles were measured 5 seconds after placing the drops on the surface. Three measurements were taken to find the average contact angle.

\section{RESULTS AND DISCUSSION}

Design and Synthesis of PEO- $b$-PHA: The design of PEO- $b$-PHA to target tunable micellar morphologies had several functional requirements: 1) Both the PEO and PHA blocks have low glass transition temperatures $\left(\mathrm{T}_{\mathrm{g}}\right),\left(\mathrm{T}_{\mathrm{g} \text { PEO }}=-60{ }^{\circ} \mathrm{C}, \mathrm{T}_{\mathrm{g}}\right.$ PHA $=-56{ }^{\circ} \mathrm{C}$ ) to facilitate micelle equilibration at room temperature when favorable solution conditions are presented. $^{79}$ 2) The large hydrophilic-hydrophobic contrast represented by the high Flory-Huggins interaction parameter drives phase separation of the blocks and enables modulation of the reorganization kinetics based upon the presented solution conditions. ${ }^{80-83}$ 3) The polymer is simple to synthesize in diverse laboratory settings by atom transfer radical polymerization (ATRP) using a chain extension from commercial PEO homopolymers. Different size PEO macroinitiators were synthesized by the esterification of commercial poly(ethylene glycol)methyl ether with 2-bromopropionic acid (Figure S1). These macroinitiators were then chain-extended using ATRP in DMF to improve polymerization kinetics. ${ }^{84}$ Please note that PHA exhibits tacticity with two different chemical environments for c protons in the backbone (Figures S2). The obtained ${ }^{1} \mathrm{H}$ NMR, ${ }^{1} \mathrm{H}-{ }^{1} \mathrm{H}$ correlation spectroscopy (COSY) and the ${ }^{1} \mathrm{H}^{13} \mathrm{C}$ heteronuclear single quantum coherence (HSQC) for PEO- $b$-PHA are shown in Figures S2-4, respectively. PEO- $b$-PHA BCPs were synthesized with different molar masses from 8-87 
$\mathrm{kg} \mathrm{mol}^{-1}$ and low molar mass dispersities of 1.061.29. The obtained dispersity values from GPC and molar masses from ${ }^{1} \mathrm{H}$ NMR are tabulated in Table I. The resulting polymers were liquid or semi-liquid at room temperature thus fulfilling the first functional requirement.

\section{PEO-b-PHA behavior and Flory-Huggins effective interaction parameter $(\chi)$}

The behavior of pure PEO- $b$-PHA polymers were investigated by small angle X-ray scattering (SAXS). The data in Figure 1 showed clear microphase separation for all polymers P1-P4, ranging from $12-87 \mathrm{~kg} \mathrm{~mol}^{-1}$.
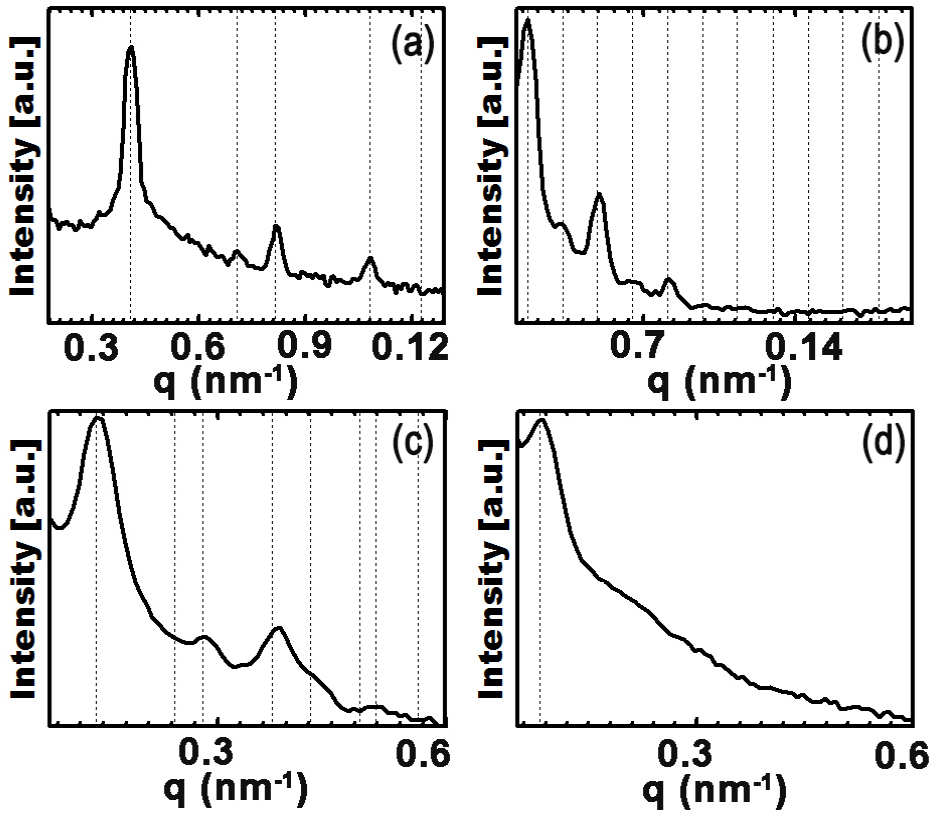

Figure 1. SAXS patterns of different PEO- $b$-PHAs in order of increasing total molar mass as measured in situ at $70{ }^{\circ} \mathrm{C}$. (a) P1 (b) P2 (c) P3 (d) P4. Dashed lines indicate the first peak followed by the allowed peaks for hexagonal $(a, c)$ or lamellar (b) symmetry.

The principle scattering peaks ranged from $\mathrm{q}=0.08$ to $0.42 \mathrm{~nm}^{-1}$, corresponding to $15.4-74.6 \mathrm{~nm}$ spacings that scaled monotonically with polymer molar mass (Table I). The low molar mass P1 formed a well-ordered morphology with numerous higher order reflections at $\left(\mathrm{q} / \mathrm{q}^{*}\right)^{2}=1,3,4$, and 7 , consistent with hexagonally packed cylinders. Polymer P2 similarly showed multiple peaks at $\left(\mathrm{q} / \mathrm{q}^{*}\right)^{2}=1,4,9,16$, and 25 for a well-ordered lamellar morphology as well as $\mathbf{P} 3$ polymer showed multiple peaks at $\left(\mathrm{q} / \mathrm{q}^{*}\right)^{2}=1,4,7,9$ for a wellordered hexagonally packed cylinder morphology. In contrast, the higher molar mass $\mathbf{P 4}$ polymer exhibited a single peak with a broad shoulder that made for equivocal interpretation of the morphology. In the solid state, significant chain entanglement for such polymers $\left(>87 \mathrm{~kg} \mathrm{~mol}^{-1}\right)$ can inhibit equilibration of more ordered morphologies, particularly with a large $\chi$ value. ${ }^{85,86}$
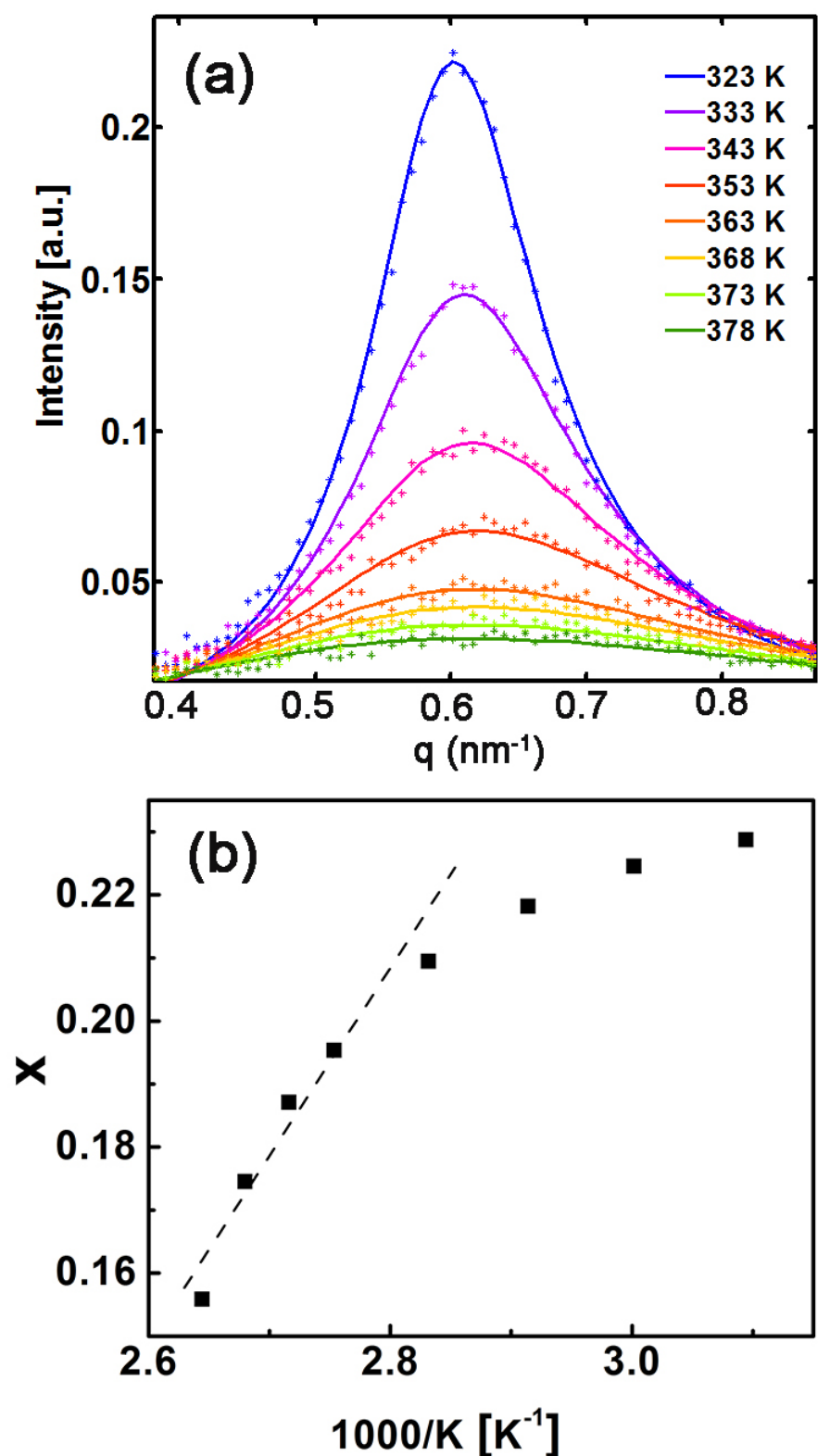

Figure 2. The SAXS profiles for the P5 taken in the disordered melt at different temperatures. The solid lines are the best fits to the experimental data $(*)$ using the random phase approximation at each temperature (a). The temperature dependence of the 
Flory-Huggins effective interaction parameter $\chi$ resulting from best-fits (b). 
The thermodynamic properties of block copolymers significantly influence their behavior both in the pure state and in solution. The Flory-Huggins effective interaction parameter $\chi$ largely corresponds to the enthalphic interactions of two species although it also includes non-combinatorial entropy. The two species interaction described by $\chi$ may either be between a polymer block and the solvent or between a pair of different polymer blocks. The magnitude of $\chi$ scales inversely with temperature where heating can be used to drive mixing rather than phase separation. ${ }^{87}$ The $\chi$ value between two polymer blocks can be determined by several methods. ${ }^{73,87,88}$ One method is to measure the order-to-disorder transition (ODT) for a series of block copolymers of the same composition but different molar masses and obtain $\chi$ from the mean field theory (MFT) prediction of the spinodal point. Of the polymers examined here, only $\mathbf{P 1}$ had an experimentally observable order-to-disorder transition temperature of $200{ }^{\circ} \mathrm{C}$. Alternatively, the application of Leibler's random phase approximation (RPA) ${ }^{73,}{ }^{89-92}$ gives multiple temperature dependent values of $\chi$ for each polymer and is useful to compare polymers of various compositions. The RPA method models the structure factor dependence of disordered melts above the ODT where mean-field theory (MFT) is well suited. A caveat is that fluctuation effects dominate near the ODT so sufficient excess temperature is needed for meaningful data. Both P5 and $\mathbf{P 6}$ had experimentally useful temperature ranges for the disordered melt above the PEO melting point and below the observed decomposition onset temperature of $240{ }^{\circ} \mathrm{C}$. Here we focus our discussion on the PHA-rich P5 that was most similar in composition to the polymers employed for coassembly. The SAXS data were collected at different temperatures with a temperature controlled sample stage. The resulting SAXS profiles were fitted using the RPA model to extract the temperature dependent values of $\chi$. The disordered phase scattering intensity $S$, can be written as a function of scattering vector $q$ as:

$$
N / S(q)=F(x, f)-2 \chi N
$$


where $x=\left(q R_{g}\right)^{2}$ and $F(x, f)$ is a combination of Debye functions which can be written as,

$$
\begin{aligned}
& F(x, f) \\
& g(f, x) g(1-f, x)-\frac{1}{4}[g(1, x)-g(f, x)-g(1-f, x)]^{2}
\end{aligned}
$$

Here $R_{g}$ is the radius of gyration of the BCP chains in the unperturbed state and $N$ is the number of lattice sites occupied using a common reference lattice volume of $0.118 \mathrm{~nm}^{3}{ }^{73,93}$ The background scattering from the mica windows was subtracted before fitting. The experimental scattering profiles were fitted using a least-squares optimization for Leibler's RPA model combined with the measured instrumental broadening factor (Figure 2a). The best-fits extracted the $\mathrm{R}_{\mathrm{g}}$ and $\chi$ at each temperature. The temperature dependence of $\chi$ was found to be $\chi$ $=274.5 / \mathrm{T}-0.5636$ for P5 (Figure 2b). A similar molar mass polymer that was PEO-rich P6 polymer yielded lower $\chi$ values (Figure S5). This nonideality may be due to the very asymmetric geometry of PHA relative to PEO. ${ }^{94}$ Thus $\chi_{\text {PEO-PHA }}=$ 0.34 was calculated at $30{ }^{\circ} \mathrm{C}$ from $\mathbf{P 5}$ for comparison to $\chi_{\mathrm{PEO}-\mathrm{PPO}}=0.085$ and $\chi_{\mathrm{PI}-\mathrm{PEO}}=0.33$ at the same temperature. ${ }^{92,95}$ Notably PEO- $b$-PHA has a 4 times larger $\chi$ value than PEO- $b$-PPOs and a slightly larger $\chi$ than PI- $b$-PEOs. Thus PEO- $b$-PHA serves as a suitable high $\chi$ polymer for the kinetic entrapment of micelles.

\section{Guidelines for Selective Tuning of Oxide Wall- Thickness}

Solution conditions may be designed to deliberately impede micelle equilibration ${ }^{96,97}$ during coassembly to preserve a persistent population or poregenerating species. This feature is key to enable isomorphic studies where changing inorganic quantities implies changing solution conditions that would otherwise impose an altered micelle size. ${ }^{70}$, 72, 97-99 Here we track the inorganic quantity with the inorganic-to-organic ratio (I:O) that compares the mass of the fully condensed oxide material to the mass of BCP, with the assumption of complete conversion of all metal containing precursors. A coassembly strategy relying on frozen or persistent micelles must consider the thermodynamic $\chi$ parameter between the solvophobic blocks and the solvent mixture. Here, the use of Hildebrand solubility parameters is insightful to estimate the thermodynamic barrier for polymer rearrangement based upon simple measurements of the intermolecular interaction strength of each species. ${ }^{74}$ The $\chi_{12}$ value scales with the square of the difference of the respective Hildebrand solubility parameters $(\delta)$ for components 1 (solvophobic block) and 2 (solvent mixture):

$$
\chi_{12}=\frac{v}{k_{b} T}\left(\delta_{1}-\delta_{2}\right)^{2}
$$

Where $v$ is the average molecular volume, $\mathrm{k}_{\mathrm{b}}$ is the Boltzmann's constant and $\mathrm{T}$ is the temperature. With a sufficient barrier for polymer rearrangement, changing the I:O ratio (oxide:polymer) changes the spacing between micelles without changing the micelle size markedly. Please note that kinetic entrapment is the key to this technique since any change in the solution solubility parameter will change the equilibrium micelle size. Such persistent micelles enable a unique level of coassembly control with independently tunable inorganic wall thickness while preserving the pore morphology. Such isomorphic yet tunable architectures provide the ideal platform for fundamental measurements of nanoscale phenomena. This approach is significantly different from equilibrating strategies that result in different morphologies with different I:O ratios. ${ }^{45,66}$

The design of conditions for PMTs has several requirements in need of consideration. 1) First and foremost the $\chi_{\text {solvophobe-solvent }}$ barrier must be sufficient to halt micelle reorganization on the timescale of film processing. This is most directly tunable by changing the composition of the solvent mixture where the resulting solubility parameter is the sum of the product of each component's solubility parameter with its volume fraction. 2) Although the dynamics of high $\chi$ BCP aqueous solutions are often immeasurable slow when quiescent, different methods of agitation were recently shown to enable the reorganization by a 
Table I: Molecular and morphological characteristics of the different PEO- $b$-PHAs employed.

\begin{tabular}{|c|c|c|c|c|c|c|c|}
\hline Name & $\begin{array}{c}\text { PEO } \\
\text { g mol }^{-1}\end{array}$ & $\begin{array}{c}\text { PHA } \\
\mathrm{g} \mathrm{mol}^{-1}\end{array}$ & $\begin{array}{l}\text { vol\% of } \\
\text { PEO }\end{array}$ & $\begin{array}{l}\text { vol\% of } \\
\text { PHA }\end{array}$ & $\begin{array}{c}\text { Molar mass } \\
\text { dispersityĐ } \\
\mathrm{m}\end{array}$ & $\begin{array}{c}\text { Bulk morphology at } \\
70^{\circ} \mathrm{C}\end{array}$ & $\begin{array}{l}\text { d-spacing } \\
\text { nm * }\end{array}$ \\
\hline P1 & 5,075 & 7,980 & 0.38 & 0.62 & 1.17 & $\begin{array}{l}\text { Hexagonally packed } \\
\text { cylinders }\end{array}$ & 15.4 \\
\hline P2 & 20,000 & 18,100 & 0.51 & 0.49 & 1.21 & Lamellar & 38.8 \\
\hline P3 & 20,000 & 43,500 & 0.300 & 0.70 & 1.16 & $\begin{array}{l}\text { Hexagonally packed } \\
\text { cylinders }\end{array}$ & 44.3 \\
\hline P4 & 20,000 & 67,300 & 0.22 & 0.78 & 1.29 & $\begin{array}{l}\text { Short-range phase } \\
\text { separation }\end{array}$ & 74.6 \\
\hline P5 & 1,900 & 9,900 & 0.15 & 0.85 & 1.14 & Disordered melt & 10.0 \\
\hline P6 & 5,100 & 2,960 & 0.62 & 0.38 & 1.06 & Disordered melt & 12.9 \\
\hline
\end{tabular}

$* \boldsymbol{d}=\frac{2 \pi}{\boldsymbol{q}}$ where $q$ is the first observed scattering peak

surface-limited exchange process at the air-solvent interface. ${ }^{99}$ A strategy preserving persistent micelles should therefore use mild stirring in lieu of aggressive agitation such as vortexing. 3) Tuning of wall-thickness with different I:O ratios may require adjustment of the solution composition to account for water consumption by hydrolyzing inorganic species. The preservation of persistent micelle templates requires that the conditions remain nonergodic after the addition of inorganic precursor. This subtle point is elaborated below where the result of hydrolysis can transition persistent micelles to become dynamic. 4) The length of the solvophobic chain determines the kinetics of micelle dynamics and was shown to have a hypersensitive double-exponential dependence. ${ }^{96}$ Thus, achieving persistent micelles requires a balance of solution conditions for sufficient $\chi$ with respect to the particular solvophobic block size, vide infra. 5) All species must remain in solution throughout the process, including the polymer, the inorganic nanoparticles, and any stabilizing ligands or acids. Most polymers are fairly hydrophobic where solvents such as methanol and water are typical precipitation agents. On the contrary, oxide nanoparticles are often soluble in rather polar solvents. The selection of suitable solvents is often rather limited where much coassembly has been carried out with THF, DMF, ${ }^{100}$ anisole, ${ }^{63}$ and toluene/butanol ${ }^{101}$ mixtures where solvents like ethanol ${ }^{102}$ and butanol ${ }^{103}$ have also worked with polymers having low $\chi$ or low molar mass. 6) Lastly, the components of solvent mixtures generally have different volatilities where evaporation leads to the enrichment of the higher boiling component and will thus change the solubility parameter of the solvent mixture during evaporation. ${ }^{80,101}$ The use of PMTs requires that the polymer chains remain under kinetic control throughout the entire process.

The morphology of a representative sample from $\mathbf{P 3}$ is described before elaborating the PMT strategy. A combination of SAXS and SEM was used to characterize each sample. The films prepared from P3 all exhibited scattering patterns with multiple well-resolved peaks. SAXS patterns from these samples revealed pronounced film texture consistent with a body centered cubic (BCC) morphology where each crystalline grain has either the [110] or [100] zone axis aligned with the film normal and with a random orientation within the sample plane. ${ }^{104}$ For example, sample P3-1.2$\mathbf{N b}_{2} \mathbf{O}_{5}$ when measured in a grazing incidence (GISAXS) geometry exhibited localized $(110)_{[110]}$ and (101) $)_{[110]}$ peaks consistent with [110] oriented BCC grains, but also included some additional intensity consistent with (110) ${ }_{\text {[100] }}$ peaks with [100] textured BCC grains (Figure 3a). The same film 


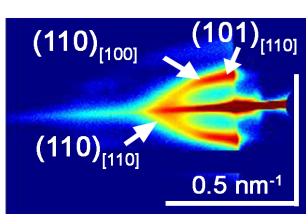

(a)

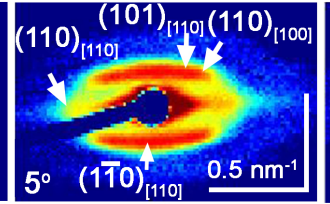

(b)

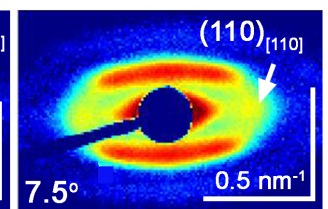

(c)

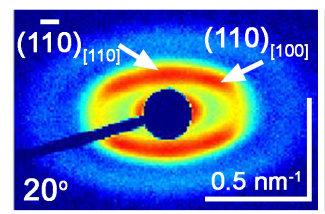

(d)

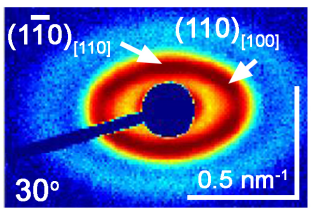

(e)
Figure 3. 2D SAXS patterns of P3-1.2- $\mathrm{Nb}_{2} \mathrm{O}_{5}$ at different incident angles from grazing incidence (a, $\alpha_{\mathrm{i}}=0.22^{\circ}$ silicon wafer) to transmission from $5-30^{\circ}$ (b-e, mica substrates). Reflections consistent with specific planes arising from specific crystalline orientations relative to the substrate are indicated with arrows and are labeled with parenthesis and bracket subscripts, respectively. All color scales correspond to the $\log$ of the X-ray intensity.

was prepared on X-ray transparent mica substrates for incident angle-dependent SAXS measurements using a transmission geometry (Figure 3b-e). As was previously calculated ${ }^{104}$ for a tilt series of this BCC mixed texture, tilting the sample at low incident angles (here $0-7.5^{\circ}$ ) preserved the $(110)_{[110]}$ peaks which then disappeared at higher incident angles (here $20^{\circ}+$ ) as a result of the finite thickness of the Ewald sphere (Figure 3d). At both $20^{\circ}$ and $30^{\circ}$ incident angle, peaks consistent with the $(110)_{[100]}$ from [100] BCC textured grains were clearly observed, strengthening the interpretation of a mixed texture BCC morphology. The scattering patterns were elongated relative to the film normal where the asymmetry was maximum near $0^{\circ}$ incident angle. The trend in elongation is indicative of film compression along the film normal and is common for coassembled systems. ${ }^{62,75,104-107}$ The $(101)_{[110]}$ peak exhibited a $d_{101}=33.9 \mathrm{~nm}^{-1}$ spacing that corresponded to a mixture of lattice constant orientations including both in-plane (uncompressed) and out-of-plane (compressed) directions. The purely in-plane lattice constant was calculated by fitting an ellipse to the elongated first ring scatting pattern corresponding to the $\{110\}$ family of planes at different orientations. The in-plane lattice parameter was calculated from the in-plane position of this ring at $\mathrm{q}_{\mathrm{z}}=0$, and yield a value of $\mathrm{a}=38.9 \mathrm{~nm}$.
SEM images of P3-1.2- $\mathbf{N b}_{2} \mathbf{O}_{5}$ after calcination exhibited a characteristic pore size (black) with a periodic niobium oxide (white) structure (Figure 4a). The in-plane orientation recorded by SEM is expected to have 2-fold symmetry for the [110] textured grains and 4-fold symmetry for the [100] textured grains. The recorded electron micrographs were consistent with both expected textures, although the local disorder complicated the interpretation. The small grain sizes were indicative of limited long-range order at the surface and led to a range of in-plane lattice parameters from 33.5$35.2 \mathrm{~nm}$. These SEM measurements of the in-plane lattice constant were similar to $38.9 \mathrm{~nm}$ in-plane lattice constant determined from GISAXS measurements after elliptical correction. GISAXS measurements on the same sample after calcination are shown in Figure S7. Thus for all subsequent P3 samples, the same elliptical fitting was used to derive the in-plane lattice constant for comparison to the in-plane SEM measurements (Table II, Figure $4)$.

A series of films were prepared using PEO- $b$-PHA to demonstrate the application of the PMT solution design guidelines and were characterized with GISAXS and SEM. The coassembly solutions all had the same amount of solvent, aqueous hydrochloric acid, and polymer at the start of processing, where the main variable was the amount of inorganic precursor added later (Table III). At this first stage extensive vortexing was used to enable micelle equilibration under thermodynamically challenging solution conditions. $^{99}$ The addition of inorganic sol precursors leads to hydrolysis reactions that lower the thermodynamic barrier to reorganizing (Figure 5 ). For PEO- $b$-PHA in THF-water mixtures, the solutions with higher water content after hydrolysis will have higher solubility parameters and different equilibrium micelle sizes. However, the use of kinetically limiting conditions enables the preservation of the micelle size distribution. Thus a significant amount of water $(3.6 \mathrm{v} \%)$ was used to favor high $\chi_{\text {PHA-solution }}$ conditions for micelles with a 

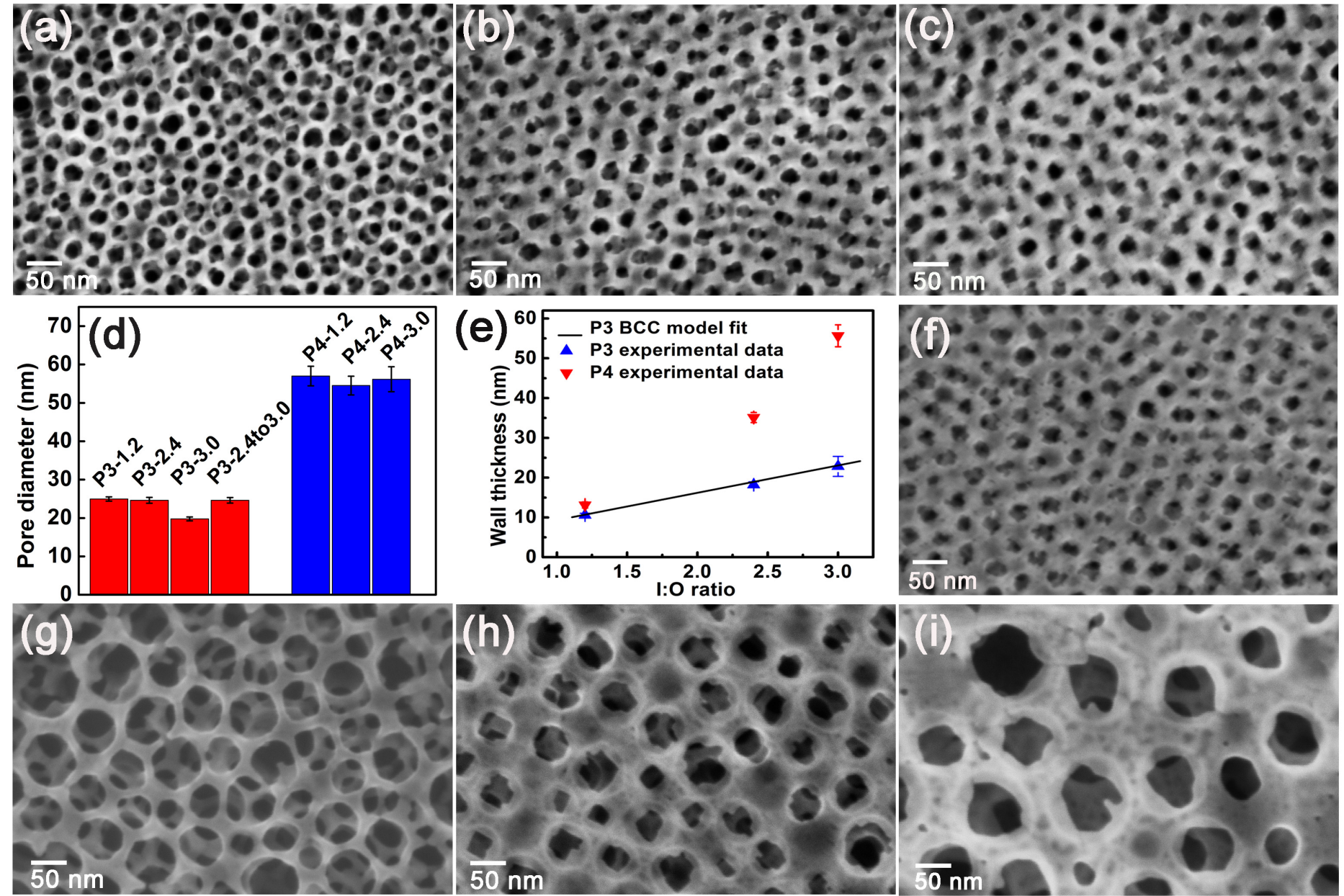

Figure 4. $\mathrm{SEM}$ images of calcined $\mathrm{Nb}_{2} \mathrm{O}_{5}$ thin films resulting from polymers P3 (a-c,f) and P4 (g-i). From left to right, the films vary by the I:O from 1.2 to 2.4 to 3.0. Film P3-2.4to3.0- $\mathbf{N b}_{2} \mathbf{O}_{5}$ (f) was made by adding additional water before adding further inorganic to reach $\mathrm{I}: \mathrm{O}=3.0$ as shown schematically in Figure 5c. Average pore diameters are preserved under proper solution conditions for both P3 and P4 samples (d). The tunable wallthickness was plotted as a function of the I:O ratio used where the data from P3 were fitted well with a simple bcc geometrical model (e).

starting solution Hildebrand parameter of 19.65 $\sqrt{\mathrm{MPa}}$ (Table III, IV). Films were dip coated from these solutions and promptly aged at elevated temperatures to drive the condensation of the inorganic material and inhibit subsequent polymer reorganization. The GISAXS patterns of all films showed the specular reflection peak, Yoneda peak, and the scattering signal from the transmitted beam. The specular reflection is located at the position where the reflected angle is equal to the incident angle forming an intense peak. Sample P3-2.4$\mathbf{N b}_{2} \mathbf{O}_{5}$ was very similar to the previously described P3-1.2- $\mathrm{Nb}_{2} \mathrm{O}_{5}$ sample, with the same lattice parameter determined by GISAXS and an indistinguishable pore size of $24.6 \pm 0.8$ vs $24.9 \pm 0.6$ $\mathrm{nm}$, respectively (Figure 4a,b, Figure 6c). Please note that here we focus on calcined samples and report the average value along with the standard error of the mean to statistically compare pore size populations with several $\mathrm{nm}$ of standard deviation. To ease sample comparison, the in-plane scattering vector $q_{y}$ is plotted for each sample (Figure 6d). Both the in-plane scattering angle $\alpha_{f}$ and the out-ofplane scattering angle $\Psi$ are used to calculate the $\mathrm{q}_{\mathrm{y}}$ component at off-specular conditions where $\alpha_{i} \neq \alpha_{f}$ and $2 \theta \neq 0:{ }^{108,109}$ 


$$
q_{y}=\frac{2 \pi \cos \alpha_{f} \sin \Psi}{\lambda}
$$

The in-plane cuts of the scattered intensity as a function of $q_{y}$ (at constant $q_{z}$ ) were extracted from the $2 \mathrm{D}$ detector images by integrating over a stripe of 10 pixels width to improve the signal-to-noise. In contrast to the similar GISAXS patterns (Figure S7c), these two samples had significantly different oxide wall-thicknesses of $10.6 \pm 0.4$ and $18.2 \pm 0.8 \mathrm{~nm}$

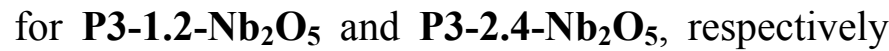
(Figure 4e, Table II). Here, doubling the I:O ratio led to a nearly doubled oxide wall-thickness while preserving the same pore structure. In contrast, further increasing the inorganic content with sample P3-3.0- $-\mathrm{Nb}_{2} \mathrm{O}_{5}$ led to a reduced pore size of $19.8 \pm 0.5 \mathrm{~nm}$ and an increased lattice spacing of $45.4 \mathrm{~nm}$. The statistically significant change in pore size indicates a dynamic micelle population that reorganized in response to the water consumption associated with the hydrolysis of niobium ethoxide (Figure 5c). Indeed, the reduced $\chi$ parameter upon addition of hydrolyzing inorganic precursors would favor an equilibrium point with reduced micelle size. Assuming complete hydrolysis that exchanges water for ethanol, the resulting solutions should have $2.73-1.43 \%$ water and $1.71-4.13 \%$ ethanol mixed with THF and would have a Hildebrand parameter of $19.53-19.34 \sqrt{ } \mathrm{MPa}$ (Table IV). ${ }^{74}$ This range of solubility parameter values for the solvent mixtures were used with the $16.64 \sqrt{\mathrm{MPa}^{74}}$ solubility parameter estimated for PHA to estime a range of $\chi_{\text {solvophobe-solvent }}$ values from $0.47-0.51$ (Table IV). These $\chi$ values are close to the transition from persistent micelles to dynamic micelles, vide infra, and are lower than more extreme $\chi=3.5^{97}$ systems to facilitate equilibration assisted by vortexing. The transition from persistent micelles to dynamic micelles (Figure 5b) is suppressed using the PMT approach and may be corrected by increasing $\chi_{\text {PHA-solution }}$ with additional water content to preserve non-ergodic conditions (Figure 5). However, adding extra water at the start of the experiment changes the starting conditions for micelle equilibration and can lead to the precipitation of the polymer. Thus a 2-step strategy was developed for P3-2.4to3.0- $\mathbf{N b}_{2} \mathrm{O}_{5}$ starting from the conditions of sample P3-2.4- $\mathbf{N b}_{2} \mathrm{O}_{5}$, followed by the addition of extra water $(\mathrm{HCl})$ to increase the $\chi_{\text {PHA-solution }}$ before the subsequent addition of further niobium ethoxide to raise the $\mathrm{I}: \mathrm{O}$ ratio to 3.0 (Figure 5c). This systematic approach is designed to preserve the original micelle population and is quantitatively documented in terms of solubility parameters in Table IV. The resulting SEM images exhibit $24.6 \pm 0.7 \mathrm{~nm}$ pores that are indistinguishable from samples P3-1.2- $\mathbf{N b}_{2} \mathrm{O}_{5}$ and P3-2.4- $\mathbf{N b}_{2} \mathrm{O}_{5}$ and indicate a return of the assembly conditions to kinetic control for PMTs (Figure 4a,b,f). SEM measurements of the oxide wall-thickness indicated an expansion to $23.8 \pm 0.8 \mathrm{~nm}$ and a correspondingly increased in-plane lattice dimension of $44.5 \mathrm{~nm}$ by SAXS (Table II). The PMT approach with P3 enabled the systematic control of wall-thickness from $10.6 \pm 0.5-23.8 \pm 0.8 \mathrm{~nm}$ while preserving an isomorphic structure with statistically indistinguishable average pore size and the same pore symmetry (Figure 4e, Table II). These observed wall-thickness for the highly ordered P3 samples agreed well with a simple geometrical model of BCC spheres of constant micelle radius with variable matrix volume as a result of the different I:O ratios:

$$
t=r \sqrt[3]{\left(\frac{\rho_{\text {org }}}{\rho_{\text {inorg }}} x+1\right) \frac{8 \pi}{3}}-2 r
$$

where $t$ is the wall-thickness, $r$ is the pore radius, $\rho_{\text {org }}$ is the PHA density, $\rho_{\text {inorg }}$ is the inorganic density and $x$ is the $\mathrm{I}: \mathrm{O}$ ratio. A natural result of this model is the expansion of the BCC lattice parameter with increasing inorganic content, as was observed by GISAXS (Table II). Samples prepared from the higher molar mass P4 exhibited similar morphology trends with larger feature sizes. The SEM images for P4 films are shown in Figure 4a-c where the wall-thickness is monotonically controllable from $13.1 \pm 0.8$ to $36.3 \pm 0.9$ to $55.7 \pm 2.8 \mathrm{~nm}$ (Figure $4 \mathrm{e}$, Table II). The significant $55.7 \mathrm{~nm}$ average wall-

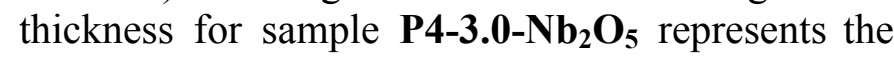
largest wall-thickness obtained from a micelle coassembly approach. ${ }^{41,67,80,110}$ In contrast to P3, the micelles of $\mathbf{P 4}$ are significantly larger and have a larger standard deviation due to the significant chain length dependence for the initial equilibration step. $^{96}$ The morphologies resulting from P4 coassembly thus had less long range order than P3, 
Table II: Average pore diameter and wall-thickness of calcined $\mathrm{Nb}_{2} \mathrm{O}_{5}$ thin films by varying the I:O ratio with $\mathbf{P 3}$ and $\mathbf{P 4}$ polymers.

\begin{tabular}{|c|c|c|c|c|c|}
\hline Sample name & $\begin{array}{c}\text { Average pore } \\
\text { diameter from } \\
\text { SEM }(\mathrm{nm})^{*}\end{array}$ & $\begin{array}{l}\text { Pore diameter } \\
\text { standard } \\
\text { deviation }(\mathrm{nm})\end{array}$ & $\begin{array}{c}\text { Average wall- } \\
\text { thickness from } \\
\text { SEM (nm)* }\end{array}$ & $\begin{array}{l}\text { In-plane d- } \\
\text { spacing from } \\
\text { GISAXS (nm) }\end{array}$ & $\begin{array}{l}\text { In-plane lattice } \\
\text { parameter } \\
\text { from SEM } \\
(\mathrm{nm})\end{array}$ \\
\hline \multicolumn{6}{|c|}{ BCC micelle morphology } \\
\hline $\mathrm{P} 3-1.2-\mathrm{Nb}_{2} \mathrm{O}_{5}$ & $24.9 \pm 0.6$ & 2.7 & $10.6 \pm 0.5$ & $38.9 * *$ & $33.5-35.2$ \\
\hline $\mathrm{P3}-2.4-\mathrm{Nb}_{2} \mathrm{O}_{5}$ & $24.6 \pm 0.8$ & 3.8 & $18.2 \pm 0.8$ & $40.4 * *$ & $41.2-45.4$ \\
\hline $\mathrm{P3}-3.0-\mathrm{Nb}_{2} \mathrm{O}_{5}$ & $19.8 \pm 0.5$ & 2.7 & $22.8 \pm 2.5$ & $45.4 * *$ & $39.08-43.5$ \\
\hline 3-2.4to3.0- $-\mathrm{Nb}_{2} \mathrm{O}_{5}$ & $24.6 \pm 0.7$ & 3.6 & $23.8 \pm 0.8$ & $44.5^{* *}$ & 41.3-51.1 \\
\hline
\end{tabular}

Disordered micelle morphology

\begin{tabular}{|c|c|c|c|c|}
\hline $\mathrm{P} 4-1.2-\mathrm{Nb}_{2} \mathrm{O}_{5}$ & $57.0 \pm 2.5$ & 11.3 & $13.1 \pm 0.8$ & $67.9 \dagger$ \\
\hline $\mathrm{P} 4-2.4-\mathrm{Nb}_{2} \mathrm{O}_{5}$ & $54.5 \pm 1.5$ & 11.8 & $36.3 \pm 0.9$ & $68.0 \dagger$ \\
\hline $\mathrm{P} 4-3.0-\mathrm{Nb}_{2} \mathrm{O}_{5}$ & $56.2 \pm 3.2$ & 14.5 & $55.7 \pm 2.8$ & $\begin{array}{c}\text { No peak was } \\
\text { observed }\end{array}$ \\
\hline
\end{tabular}

* where the average is reported \pm the error of the mean

** in-plane lattice parameter $\mathrm{a}=\frac{2 \pi \sqrt{2}}{\boldsymbol{q}_{[1 \overline{1} \mathbf{0}]}}$ after fitting an ellipse to the scattering pattern

$\dagger$ where $\boldsymbol{d}=\frac{2 \pi}{q}$ from the first scattering peak for disordered micelles

which is as expected for a polymer that forms only short-range ordered structures in the pure state after annealing (Figure 1d). The pore sizes for P4-1.2$\mathbf{N b}_{2} \mathbf{O}_{5}$ and $\mathbf{P 4 - 3 . 0}-\mathbf{N b}_{2} \mathrm{O}_{5}$ were statistically indistinguishable at $57.0 \pm 2.5$ and $56.1 \pm 3.2 \mathrm{~nm}$, respectively. Interestingly, the same $\mathrm{I}: \mathrm{O}=3.0$ solution conditions that failed to kinetically trap the smaller molar mass $\mathbf{P 3}$ were able to kinetically trap the larger molar mass $\mathbf{P 4}$ micelles. This demonstrates that the critical value of $\chi_{\text {solvophobe-solvent }}$ is dependent on the molar mass of the solvophobe, as expected. ${ }^{96}$ GISAXS patterns of most P4 samples produced several in-plane spots that elongated along $\mathrm{q}_{\mathrm{z}}$ (Figure 6b,d). Considering the width of the pore size distribution for $\mathbf{P 4}$ samples (Table II), it is not surprising that the SEM images appear to be a disordered packing of spheres (Figure 4g-i). The periodicity of GISAXS peaks from P4 films were attributed to the random packing of spheres ${ }^{111}$ based upon the disorder observed by SEM (Figure 4g-i). Such random packing of hard-spheres can have multiple peaks resulting from the radial distribution function where there may not be a simple relationship for the observed scattering peak to the physical dimensions of the system. ${ }^{11}$ In particular P4-3.0- $\mathrm{Nb}_{2} \mathrm{O}_{5}$ did not exhibit a clear scattering peak, but rather a shoulder near $\mathrm{q}=\sim 0.08 \mathrm{~nm}^{-1}$, indicating a decrease in long range order (Figure 6d). These samples demonstrate the application of a robust conceptual map for tunable nanofabrication with 

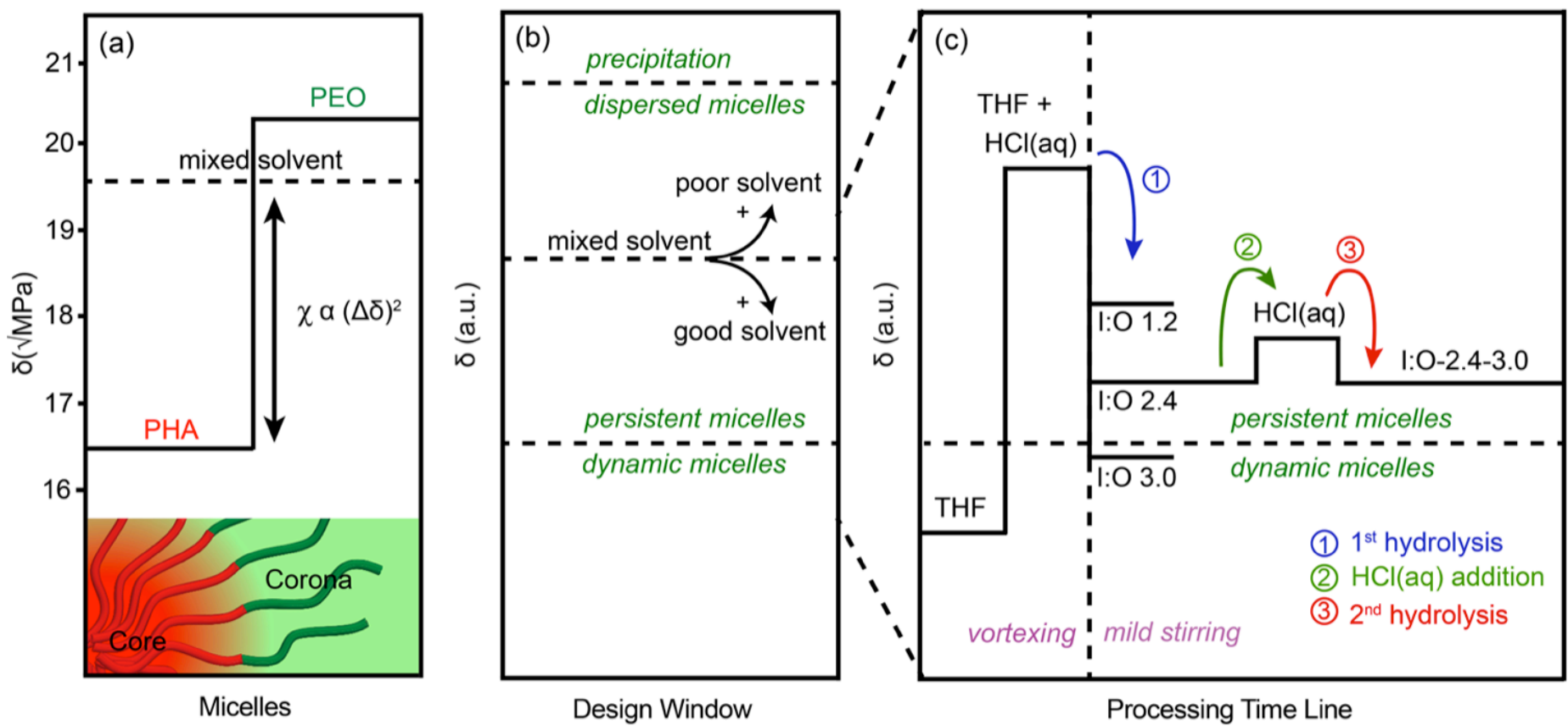

Figure 5. Plots of Hildebrand solubility parameters for designing persistent micellar templates. The tunable separation of solubility parameters between the solvophobic block and the solvent (a) estimate the thermodynamic barrier to micelle reorganization. Under vigorous mixing $\left(\mathrm{THF}+\mathrm{HCl}_{(\mathrm{aq})}\right)$, the system may equilibrate where as mild stirring conditions result in persistent micelles (b). Coassembly strategies for PMTs must maintain solution conditions for micelles that are dispersed and non-dynamic, or persistent (b). Under vigorous vortexing $\left(\mathrm{THF}+\mathrm{HCl}_{(\mathrm{aq})}\right)$, the system progresses towards equilibrium whereas mild stirring conditions preserve persistent micelles (c). The addition of inorganic components shifts the solution conditions through hydrolysis (c) and may be accounted for with rational changes to the solution conditions to preserve persistent micelles.

Table III: Synthesis quantities for mesoporous $\mathrm{Nb}_{2} \mathrm{O}_{5}$ with varying I:O ratios.

\begin{tabular}{|l|l|l|l|l|l|l|}
\hline \multicolumn{1}{|c|}{ Sample name } & \multicolumn{1}{|c|}{$\begin{array}{c}\text { I/O } \\
\text { ratio* }\end{array}$} & $\begin{array}{c}\text { Nb(OEt) } \\
(\mathbf{m L})\end{array}$ & $\begin{array}{c}\text { THF } \\
(\mathbf{m L})\end{array}$ & $\begin{array}{c}\text { Polymer } \\
(\mathrm{mg})\end{array}$ & $\begin{array}{c}\text { HCl } \\
(\mathbf{m L})\end{array}$ & \multicolumn{1}{|c|}{$\begin{array}{c}\text { Polymer } \\
\text { wt\% }\end{array}$} \\
\hline $1.2-\mathrm{Nb}_{2} \mathrm{O}_{5}$ & 1.2 & 0.051 & 2.0 & 22.4 & 0.1 & 1.18 \\
\hline $2.4-\mathrm{Nb}_{2} \mathrm{O}_{5}$ & 2.4 & 0.102 & 2.0 & 22.4 & 0.1 & 1.09 \\
\hline $3.0-\mathrm{Nb}_{2} \mathrm{O}_{5}$ & 3.0 & 0.128 & 2.0 & 22.4 & 0.1 & 1.08 \\
\hline $2.4 t 03.0-\mathrm{Nb}_{2} \mathrm{O}_{5}$ & 3.0 & 0.128 & 2.0 & 22.4 & 0.106 & 1.07 \\
\hline
\end{tabular}

${ }^{*} \mathrm{I}$ :O ratio is the $\mathrm{Nb}_{2} \mathrm{O}_{5}$ oxide-to-polymer mass ratio in the final hybrid material assuming complete conversion of oxide precursors. 
Table IV: Solution composition and Hildebrand parameters of the P3 films during the processing steps.

\begin{tabular}{|c|c|c|c|c|}
\hline Sample name & $\begin{array}{c}\text { Initial water } \\
\quad \text { vol\% }\end{array}$ & $\begin{array}{c}\text { Expected final } \\
\text { water } \\
\text { vol\% }\end{array}$ & $\begin{array}{c}\delta \\
\text { THF+HCl }\end{array}$ & $\begin{array}{c}\delta \\
\text { After hydrolysis }\end{array}$ \\
\hline $\mathrm{P3}-1.2-\mathrm{Nb}_{2} \mathrm{O}_{5}$ & 3.60 & 2.73 & 19.65 & 19.53 \\
\hline $\mathrm{P3}-2.4-\mathrm{Nb}_{2} \mathrm{O}_{5}$ & 3.60 & 1.86 & 19.65 & 19.41 \\
\hline $\mathrm{P3}-3.0-\mathrm{Nb}_{2} \mathrm{O}_{5}$ & 3.60 & 1.43 & 19.65 & 19.34 \\
\hline $\mathrm{P3}-2.4$ to3.0- $-\mathrm{Nb}_{2} \mathrm{O}_{5}$ * & 3.82 & 1.64 & 19.65 & 19.41 \\
\hline
\end{tabular}

*Starting from I:O 2.4 conditions, the solution $\delta$ was increased by adding more $\mathrm{HCl}$ to allow for a further addition of niobium ethoxide to reach an I:O ratio of 3.0. See Figure 5c.
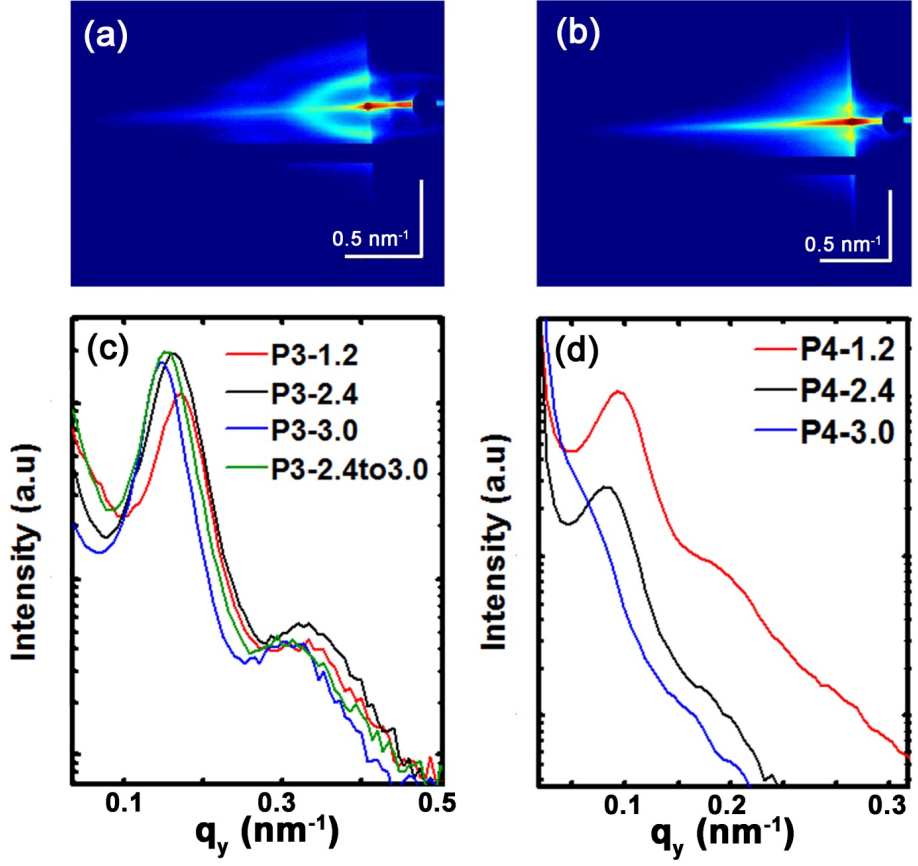

Figure 6. 2D GISAXS images measured at an incidence angle of $\alpha_{i}=0.22^{\circ}$ for as-made P3-1.2-

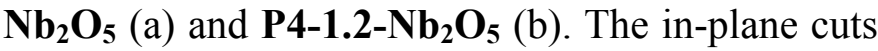
of the scattered intensity as a function of $q y$ (at constant $q z$ ) were extracted from the 2D images. 2D image color scales correspond to the log of the Xray intensity.

micelles using semi-quantitative guidelines to achieve tunable isomorphic structures from persistent micelle templates. The precise control of pore-size and wall-thickness in the in-plane direction is crucial to a variety of electrochemical devices where transport within the electrolyte and within the oxide both primarily occur normal to the substrate.
Please note that "persistent micelles" do not imply equilibrated micelles at any stage of the processing. Considering the large molar masses and kinetically challenging conditions used here, one should not expect the micelles to fully equilibrate on a laboratory time scale. ${ }^{99}$ The effect of the vortexing time and the enthalpic barrier to reorganization (final water content) were studied using P3 (Figure S8). As expected, the average micelle diameters monotonically increased with increasing the final water content in the coassemble solutions (Figure S8 a-c). Comparing different vortexing times, 5 vs $60 \mathrm{~min}$, increasing average micelle sizes were observed with extended agitation, with a more significant effect for samples with higher water content (Figure S8d-f). These data evidence slower equilibration kinetics with increasing $\chi_{\text {PHA-solvent }}$ and suggest that much longer agitation times could be used to achieve more-equilibrated and yet larger pore sizes with a given polymer. The GISAXS data for all the $60 \mathrm{~min}$ vortexed samples showed lower $\mathrm{q}$ values than the corresponding $5 \mathrm{~min}$ vortexed samples, consistent with the formation of larger unit cell lattice parameters (Figure S9 h).

\section{Crystallization of Oxide Nanostructures}

GIWAXS measurements were made on the $\mathrm{Nb}_{2} \mathrm{O}_{5}$ thin films after calcination to $600{ }^{\circ} \mathrm{C}$ to demonstrate highly crystalline materials (Figure S9). The resulting patterns all showed intense isotropic peaks that were consistent with the formation of orthorhombic $\mathrm{Nb}_{2} \mathrm{O}_{5}$ (PDF \#27- 
Table V: Characterization of different mesoporous inorganic systems after calcination.

\begin{tabular}{|c|c|c|c|c|}
\hline $\begin{array}{l}\text { Inorganic } \\
\text { system }\end{array}$ & $\begin{array}{l}\text { Average } \\
\text { pore } \\
\text { diameter } \\
\text { from SEM } \\
(\mathrm{nm})^{*}\end{array}$ & $\begin{array}{l}\text { Pore } \\
\text { diameter } \\
\text { standard } \\
\text { deviation } \\
(\mathrm{nm})\end{array}$ & $\begin{array}{l}\text { Average } \\
\text { wall- } \\
\text { thickness } \\
\text { from } \\
\text { SEM } \\
(\mathrm{nm})^{*}\end{array}$ & $\begin{array}{l}\text { GISAXS } \\
\text { d- } \\
\text { spacing } \\
(\mathrm{nm})^{* *}\end{array}$ \\
\hline $\mathrm{WO}_{3}$ & $35.0 \pm 1.4$ & 6.0 & $26.2 \pm 1.1$ & 51.1 \\
\hline $\mathrm{SiO}_{2}$ & $75.2 \pm 2.9$ & 13.0 & $16.3 \pm 0.6$ & $\begin{array}{l}\text { No } \\
\text { peaks }\end{array}$ \\
\hline
\end{tabular}

* where the average is reported \pm the error of the mean

$* * d=\frac{2 \pi}{q}$ where the first scattering peak for the disordered micelles

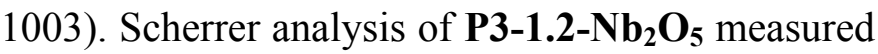
with a transmission geometry on a mica substrate led to an estimated average crystallite size of $7.7 \mathrm{~nm}$ that was smaller than the above reported wallthicknesses. In contrast to Pluronic based coassembly approaches, the large feature sizes accessible with higher molar mass polymers enables larger feature sizes that easily survive the formation of crystallites with high temperature heat treatments.

The calcination of porous films also induced compression along the out-of-plane direction, normal to the substrate. Anisotropic film compression is widely reported and expected for a substrate-supported porous film where the in-plane constraint of substrate dimensions causes significant compression in the out-of-plane direction as the inorganic densifies and crystallizes. ${ }^{112}$ In the out-ofplane direction, the pores shrank by $58.2 \%$ for P31.2- $-\mathrm{Nb}_{2} \mathrm{O}_{5}$ as evidenced by cross-sectional SEM (Figure S10). A similar extent of film contraction was reported for sol-gel derived $\mathrm{TiO}_{2}$ thin films with $47.7 \%$ shrinkage. ${ }^{113}$ For comparison, the outof-plane lattice contraction was obtained by GISAXS. The out-of-plane lattice parameter was obtained by fitting an ellipse to the (110) peak to extract the purely out-of-plane component as 9.8 $\mathrm{nm}$. The observed out-of-plane lattice contraction of $74.9 \%$ was larger than the contraction of the pores in the same direction, indicating shrinkage of the walls in the out-of-plane direction.

Ellipsometry porosimitry (EP) measurements were performed on P3-1.2- $\mathrm{Nb}_{2} \mathrm{O}_{5}$ thin films. Type IV isotherms ${ }^{114}$ were observed (Figure 7a). A TaucLorentz dispersion law was applied to the data to obtain values of the refractive index at each humidity point, corresponding to the adsorption of water molecules into the pores. ${ }^{76}$ Note that the samples were measured at incremental steps of 0.01 relative humidity to acquire sufficient data points for a well-defined isotherm. The plateau for the adsorption isotherm was reached at a relative pressure of 0.95 , indicating that the pores were completely filled. The corresponding pore diameter distribution (PDD) based on a modified Kelvin formula $^{78}$ is shown in Figure $7 \mathrm{~b}$. Based on SEM image analysis, we accounted for the ellipsoidal shape of the pores with an anisotropy ratio of 2.4 between the in-plane and out-of-plane diameter. A modified Kelvin model that accommodates for the pore anisotropy by a geometric coefficient $\mathrm{G}$ was consequently used. ${ }^{78}$ Furthermore a contact angle of $43^{\circ}$ was taken into account, as experimentally determined for water on a flat sol-gel derived $\mathrm{Nb}_{2} \mathrm{O}_{5}$ film (Figure S11). The results for a mean in-plane and out-of-plane pore diameter of $25.5 \mathrm{~nm}$ and 10.8 $\mathrm{nm}$, respectively are well in line with data obtained from SEM image analysis, where values of $24.9 \mathrm{~nm}$ and $10.6 \mathrm{~nm}$ were determined.

\section{Generalization to Diverse Oxides and Pore Size Tuning}

The compatibility of micellar templating strategies using PEO- $b$-PHA with diverse oxides was 

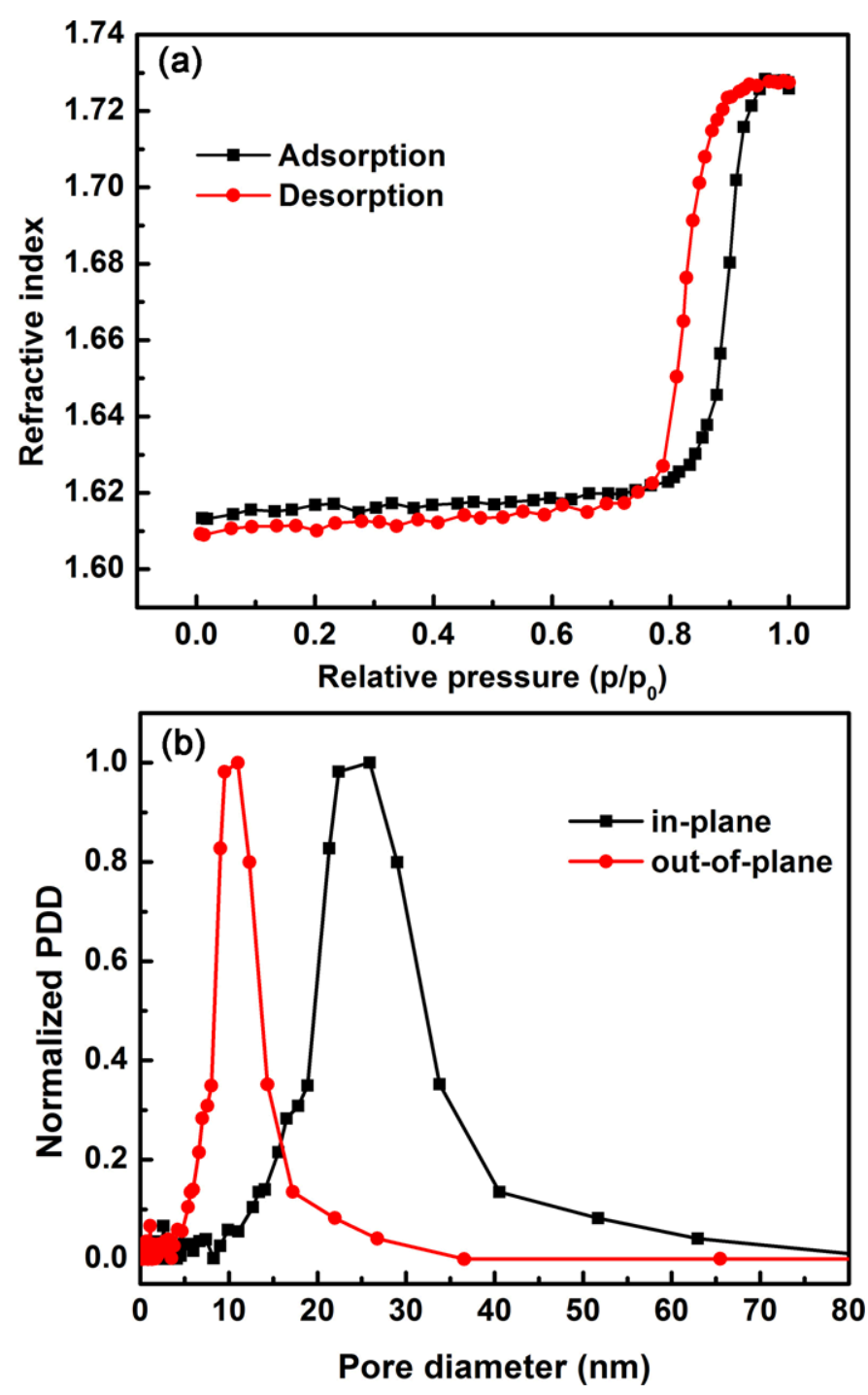

Figure 7. Ellipsometric porosimetry of P3-1.2$\mathbf{N b}_{2} \mathbf{O}_{5}$ sample. Refractive index isotherm (a) that corresponds to the adsorption of water molecules into the pores. In-plane and out-of-plane pore diameter distributions (PDD) were obtained from a modified Kelvin model for ellipsoidal mesopores (b). ${ }^{78}$

elaborated with $\mathrm{WO}_{3}$ and $\mathrm{SiO}_{2}$. The resulting porous $\mathrm{WO}_{3}$ and $\mathrm{SiO}_{2}$ films were composed of similar spherical pores as discussed above for numerous $\mathrm{Nb}_{2} \mathrm{O}_{5}$ samples. SEM images of both the as-made and calcined films of $\mathrm{WO}_{3}$ and $\mathrm{SiO}_{2}$ (Figure 8) are consistent with disordered spherical

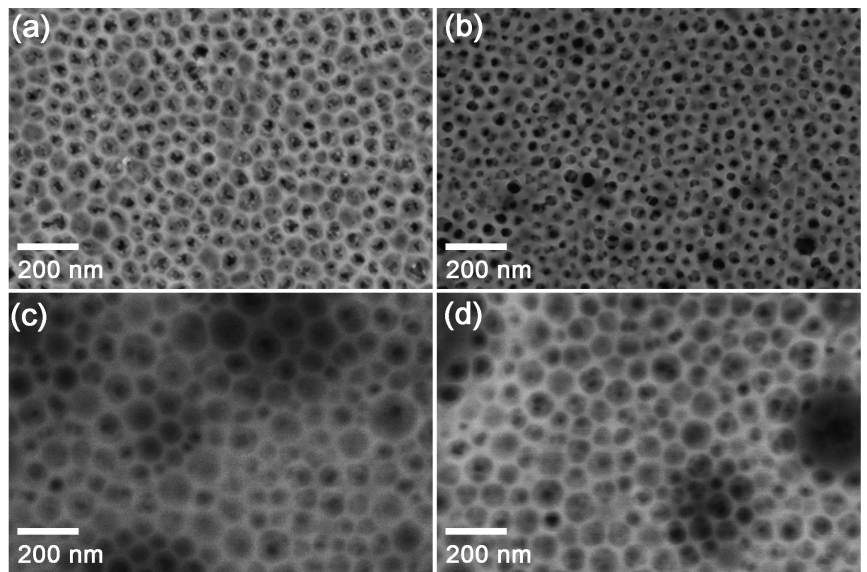

Figure 8. SEM images of various inorganic coassembled systems with $\mathbf{P 4}$ polymer: As-made (a) $\mathrm{WO}_{3}$ and (c) $\mathrm{SiO}_{2}$, as well as calcined (b) $\mathrm{WO}_{3}$ and (d) $\mathrm{SiO}_{2}$.

Table VI: Parameters correlated to the final pore size for micelle scaling relationships

\begin{tabular}{|c|c|c|c|}
\hline Sample name & $\mathbf{N}_{\text {PHA }}$ & $\begin{array}{l}\chi_{\text {solvophobe- }} \\
\text { solvent }\end{array}$ & $\begin{array}{l}\text { Pore } \\
\text { diameter } \\
(\mathbf{n m})\end{array}$ \\
\hline $\mathrm{P} 2-\mathrm{Nb}_{2} \mathrm{O}_{5}$ & 116.0 & 0.46 & 19.5 \\
\hline $\begin{array}{l}\mathrm{P3}-1.2-\mathrm{Nb}_{2} \mathrm{O}_{5}-5 \mathrm{~min} \\
\text { vortex }\end{array}$ & 278.8 & 0.56 & 24.9 \\
\hline $\begin{array}{l}\mathrm{P3}-2.4-\mathrm{Nb}_{2} \mathrm{O}_{5}-5 \mathrm{~min} \\
\text { vortex }\end{array}$ & 278.8 & 0.63 & 26.6 \\
\hline $\begin{array}{l}\mathrm{P3}-3.0-\mathrm{Nb}_{2} \mathrm{O}_{5}-5 \mathrm{~min} \\
\text { vortex }\end{array}$ & 278.8 & 0.71 & 28.9 \\
\hline $\begin{array}{l}\mathrm{P} 3-1.2-\mathrm{Nb}_{2} \mathrm{O}_{5}-60 \mathrm{~min} \\
\text { vortex }\end{array}$ & 278.8 & 0.56 & 25.3 \\
\hline $\begin{array}{l}\mathrm{P3}-2.4-\mathrm{Nb}_{2} \mathrm{O}_{5}-60 \mathrm{~min} \\
\text { vortex }\end{array}$ & 278.8 & 0.63 & 28.9 \\
\hline $\begin{array}{l}\mathrm{P3}-3.0-\mathrm{Nb}_{2} \mathrm{O}_{5}-60 \mathrm{~min} \\
\text { vortex }\end{array}$ & 278.8 & 0.71 & 32.1 \\
\hline $\mathrm{P}_{4}-\mathrm{WO}_{3}$ & 431.4 & 0.52 & 35.0 \\
\hline $\mathrm{P}_{4}-\mathrm{Nb}_{2} \mathrm{O}_{5}$ & 431.4 & 0.56 & 57.0 \\
\hline $\mathrm{P}_{4}-\mathrm{SiO}_{2}$ & 431.4 & 0.68 & 75.2 \\
\hline
\end{tabular}

micelles, as we previously found for the same $\mathbf{P 4}$ polymer with $\mathrm{Nb}_{2} \mathrm{O}_{5}$. The calcined films were crack free and the pore structure was well preserved. Very large $75.2 \pm 2.9 \mathrm{~nm}$ diameter pores were observed by SEM for $\mathrm{SiO}_{2}$ which was attributed to the additional water content associated with optimized sol recipes that naturally favor larger micelles (Table V). The corresponding GISAXS profiles for $\mathrm{WO}_{3}$ showed a distinct peak at $0.123 \mathrm{~nm}^{-1}$ corresponding $51.1 \mathrm{~nm}$ 



Figure 9. GISAXS measurements were used to extract the in-plane scattering intensity as a function of $q y$ (at constant $q z$ ) for (a) $\mathrm{WO}_{3}$ and (c) $\mathrm{SiO}_{2}$. (2D images inset). GIWAXS measurements for (b) $\mathrm{WO}_{3}$ experimental were most consistent with orthorhombic $\mathrm{WO}_{3}$ PDF \# 89-4479 where as the (d) $\mathrm{SiO}_{2}$ remained amorphous. All 2D image color scales correspond to the $\log$ of the X-ray intensity.

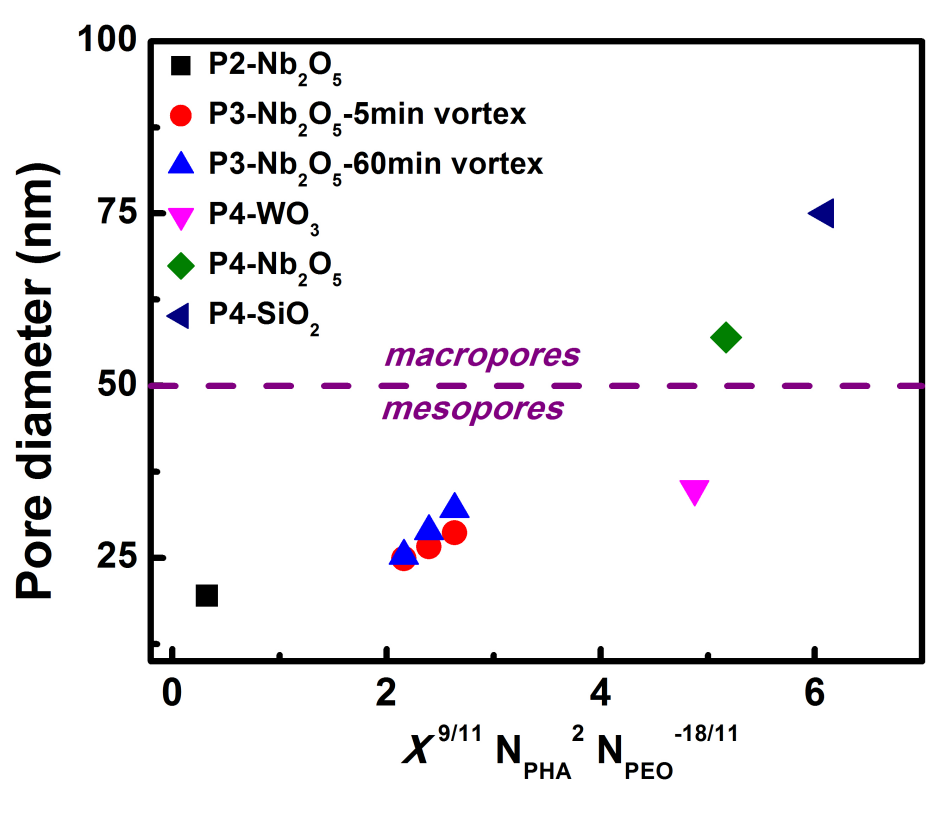

Figure 10. A wide range of pore sizes were accessible by changing the polymer block lengths and/or the solution conditions. Pore sizes scaled monotonically with the scaling relationship for intermediate micelles. Here, the core radius and thus the resulting pore diameter should scale linearly with $\chi^{9 / 11} \mathrm{~N}_{\mathrm{PHA}}{ }^{2} \mathrm{~N}_{\mathrm{PEO}}{ }^{-18 / 11}$

periodicity (Figure 9a, Table V). In contrast, GISAXS data for $\mathrm{SiO}_{2}$ did not exhibit clear peaks (Figure 9c). As with $\mathrm{Nb}_{2} \mathrm{O}_{5}$, both $\mathrm{WO}_{3}$ and $\mathrm{SiO}_{2}$ survived high temperature calcination to $600{ }^{\circ} \mathrm{C}$. The GIWAXS data obtained for $\mathrm{WO}_{3}$ calcined films showed intense isotropic peaks that were indexed as orthorhombic $\mathrm{WO}_{3}$ (Figure 8b, PDF\#89-4479) while $\mathrm{SiO}_{2}$ remained amorphous at this temperature (Figure 9d).

\section{Tunable Pore Size with Solution Conditions and Molar Mass}

Continuous access from mesoporous structures to macropores structures is demonstrated with two control parameters: 1) changing the molar mass of the PEO- $b$-PHA block copolymers and 2) by changing the water content during the micelle equilibration stage (Figure 5c). The average pore size for a wide variety of samples is shown in Figure 10. For example, the several samples prepared with $\mathbf{P 4}$ demonstrate multiple pore sizes as 
a result of the different water content in the starting solutions (Table VI). Here, higher water content increases the $\chi_{\text {solvophobe-solvent which favors a }}$ reduction of total system surface area by expanding the micelles and increasing the aggregation number at the expense of chain stretching. The pore size resulting from polymer micelles was crudely correlated to the assembly conditions using a scaling relationship for equilibrated intermediate micelles. ${ }^{115,} 116$ Here, the micelle core radius is proportional to $\chi^{9 / 11} \mathrm{~N}_{\mathrm{PHA}}{ }^{2} \mathrm{~N}_{\mathrm{PEO}}{ }^{-18 / 11}$ where $\mathrm{N}_{\mathrm{PHA}}$ is the degree of polymerization of PHA and $\mathrm{N}_{\mathrm{PEO}}$ is the degree of polymerization of PEO. Here we assume that with persistent micelles, the final pore diameter after calcination scales linearly with the hydrodynamic core diameter. In this study the data obtained were most consistent with an intermediate micelle model that includes the free-energy of the corona and assumes a majority of the hydrophobic block. ${ }^{116}$ Despite the use of non-fully equilibrated micelle solutions (Figure S8), this scaling relationship yielded significant predictive power for correlating changes in both polymer molar mass and in $\chi_{\text {solvophobe-solvent }}$ to the resulting pore size. Notably, the $\mathrm{WO}_{3}$ sample had smaller pores then predicted by this scaling model which was attributed to the more protic conditions resulting from $\mathrm{WCl}_{6}$ hydrolysis. More protic conditions could increase the ionic-repulsion of the corona to favor lower aggregation numbers. We also note that $\mathrm{P} 2-\mathrm{Nb}_{2} \mathrm{O}_{5}$ deviated slightly from the intermediate model, where such PEO-rich SDAs would likely follow a star-like model. Remarkably, the PMT strategy based upon PEO- $b$-PHA enabled access to pore sizes ranging from 20 to $75 \mathrm{~nm}$ that span from mesopores all the way into the macropore regime. This broad range of pore sizes bridges the gap normally found between polymer coassembly and colloidal templating.

\section{CONCLUSIONS}

Solution processing guidelines were presented to enable the persistent micellar templating of isomorphic nanostructures. Such architectures are ideal for nanomaterials development with adjustable inorganic wall-thickness and seamless access from mesoporous structures to macropores structures. Under appropriate solutions conditions, a simple adjustment of inorganic-to-organic ratio changes the micelle-to-micelle distance without changing the nominal micelle size. A newly reported PEO- $b$ PHA was used to demonstrate this design concept where the use of a sufficiently high $\chi_{\text {solvophobe-solution }}$ contrast is the key to maintain persistent micelle templates regardless of changing equilibrium conditions. This robust design strategy enabled the achievement of mesopores and macropores with a single design strategy that fills the gap typically found between block copolymer routes and colloidal templating. The resulting materials were high temperature stable and enabled the formation of multiple crystalline transition metal oxide frameworks.

\section{ASSOCIATED CONTENT}

\section{Supporting Information}

The Supporting Information is available free of charge on the ACS Publications website at DOI:

Detailed structure analysis of PEO- $b$-PHA polymer using ${ }^{1} \mathrm{H}$ NMR, GPC, ${ }^{1} \mathrm{H}-{ }^{1} \mathrm{H}$ COSY and $\left\{{ }^{13} \mathrm{C}\right\}$ HSQC; SAXS profiles for the P6 polymer; Sketch of the scattering geometry used in GISAXS and GIWAXS; 2D GISAXS and line extractions for calcined P3 and P4 derived mesoporous niobia films; SEM images and GISAXS line extractions for mesoporous $\mathrm{Nb}_{2} \mathrm{O}_{5}$ films made with different final water content; GIWAXS data for mesoporous $\mathrm{Nb}_{2} \mathrm{O}_{5}$ films made with different I:O ratios; SEM cross-section of calcined $\mathrm{P} 3-1.2-\mathrm{Nb}_{2} \mathrm{O}_{5}$ showing the outer-plane compression; Contact angel of flat solgel derived $\mathrm{Nb}_{2} \mathrm{O}_{5}$ film after calcination

\section{AUTHOR INFORMATION}

\section{Corresponding Author}

*morgan@stefikgroup.com 


\section{ACKNOWLEDGEMENT}

MS thanks the University of South Carolina for start-up funds. AJ thanks ACS Project SEED for financial support. This work made use of the South Carolina SAXS Collaborative, supported by the NSF Major Research Instrumentation program (award \#DMR-1428620). The authors are thankful to A. Nese for his helpful suggestions and guidance with the synthesis of BCP. In particular, we thank the NMR facility at USC and P. J. Pellechia for his help with COSY and HSQC analysis. We thank M. S. Ganewatta for his help with image processing and B. Lamm for his help with MALTAB programming and A. Sarkar for providing poly(hexyl acrylate) homopolymers. The authors thank T. W. Knight, T. Martin and C. Terrapin for help with the Helium pycnometer measurements. The authors thank John R. Regalbuto and Qiuli Liu for the help with $\mathrm{N}_{2}$ physisorption measurements. The authors thank Qian Wang and M. S. Ganewatta for assistance with contact angle measurements. SG is grateful for support by a start-up fund from University College London, Department for Chemical Engineering. BR acknowledges support by a EPSRC Case Award Studentship EP/M506448/1

\section{REFERENCES}

1. O'Regan, B.; Gratzel, M., A low-cost, high-efficiency solar cell based on dyesensitized colloidal $\mathrm{TiO} 2$ films. Nature 1991, 353, 737.

2. Bach, U.; Lupo, D.; Comte, P.; Moser, J. E.; Weissortel, F.; Salbeck, J.; Spreitzer, H.; Gratzel, M., Solid-state dye-sensitized mesoporous $\mathrm{TiO} 2$ solar cells with high photon-to-electron conversion efficiencies. Nature 1998, 395, 583.

3. Kojima, A.; Teshima, K.; Shirai, Y.; Miyasaka, T., Organometal Halide Perovskites as Visible-Light Sensitizers for Photovoltaic Cells. J. Am. Chem. Soc. 2009, 131, 6050 .

4. Sudant, G.; Baudrin, E.; Larcher, D.; Tarascon, J.-M., Electrochemical lithium reactivity with nanotextured anatase-type TiO2. J. Mater. Chem. 2005, 15, 1263.

5. Docampo, P.; Guldin, S.; Stefik, M.; Tiwana, P.; Orilall, M. C.; Hüttner, S.; Sai, H.; Wiesner, U.; Steiner, U.; Snaith, H. J., Control of Solid-State Dye-Sensitized Solar Cell Performance by Block-CopolymerDirected TiO2 Synthesis. Adv. Funct. Mater. 2010, 20, 1787.

6. Rhodes, C. P.; Long, J. W.; Pettigrew, K. A.; Stroud, R. M.; Rolison, D. R., Architectural integration of the components necessary for electrical energy storage on the nanoscale and in 3D. Nanoscale 2011, 3, 1731 .

7. Bai, H.; Li, X.; Hu, C.; Zhang, X.; Li, J.; Yan, Y.; Xi, G., Large-Scale, ThreeDimensional, Free-Standing, and Mesoporous Metal Oxide Networks for High-Performance Photocatalysis. Sci. Rep. 2013, 3 .

8. Arthur, T. S.; Bates, D. J.; Cirigliano, N.; Johnson, D. C.; Malati, P.; Mosby, J. M.; Perre, E.; Rawls, M. T.; Prieto, A. L.; Dunn, B., Three-dimensional electrodes and battery architectures. MRS Bull. 2011, 36, 523.

9. Ye, Y.; Jo, C.; Jeong, I.; Lee, J., Functional mesoporous materials for energy applications: solar cells, fuel cells, and batteries. Nanoscale 2013, 5, 4584.

10. Batmunkh, M.; Shearer, C. J.; Biggs, M. J.; Shapter, J. G., Nanocarbons for mesoscopic perovskite solar cells. J. Mater. Chem. A 2015, 3, 9020.

11. Hart, R. W.; White, H. S.; Dunn, B.; Rolison, D. R., 3-D Microbatteries. Electrochem. Commun. 2003, 5, 120.

12. Green, M. A.; Ho-Baillie, A.; Snaith, H. J., The emergence of perovskite solar cells. Nat Photon 2014, 8, 506.

13. Mei, A.; Li, X.; Liu, L.; Ku, Z.; Liu, T.; Rong, Y.; Xu, M.; Hu, M.; Chen, J.; Yang, Y.; Grätzel, M.; Han, H., A holeconductor-free, fully printable mesoscopic perovskite solar cell with high stability. Science 2014, 345, 295. 
14. Stefik, M.; Heiligtag, F. J.; Niederberger, M.; Grätzel, M., Improved Nonaqueous Synthesis of $\mathrm{TiO} 2$ for Dye-Sensitized Solar Cells. ACS Nano 2013, 7, 8981.

15. Bruce, P. G.; Scrosati, B.; Tarascon, J.-M., Nanomaterials for Rechargeable Lithium Batteries. Angew. Chem. Int. Ed. 2008, 47, 2930.

16. Kim, M. G.; Cho, J., Reversible and HighCapacity Nanostructured Electrode Materials for Li-Ion Batteries. Adv. Funct. Mater. 2009, 19, 1497.

17. Augustyn, V.; Simon, P.; Dunn, B., Pseudocapacitive oxide materials for highrate electrochemical energy storage. Energy Environ. Sci. 2014, 7, 1597.

18. Yong Hui, L.; Stefik, M.; Heiniger, L. P.; Peng, G.; Sang Il, S.; Gratzel, M.; Nazeeruddin, M. K., In Power from the sun: Perovskite solar cells. Photovoltaic Specialist Conference (PVSC), 2014, 0943.

19. Arico, A. S.; Bruce, P.; Scrosati, B.; Tarascon, J.-M.; van Schalkwijk, W., Nanostructured materials for advanced energy conversion and storage devices. Nat Mater 2005, 4, 366.

20. Sivula, K.; Le Formal, F.; Grätzel, M., Solar Water Splitting: Progress Using Hematite $\quad(\alpha-\mathrm{Fe} 2 \mathrm{O} 3) \quad$ Photoelectrodes. ChemSusChem 2011, 4, 432.

21. Lin, Y.; Yuan, G.; Sheehan, S.; Zhou, S.; Wang, D., Hematite-based solar water splitting: challenges and opportunities. Energy Environ. Sci. 2011, 4, 4862.

22. Hamann, T. W., Splitting water with rust: hematite photoelectrochemistry. Dalton Trans. 2012, 41, 7830.

23. Wang, Y.; Tang, J.; Peng, Z.; Wang, Y.; Jia, D.; Kong, B.; Elzatahry, A. A.; Zhao, D.; Zheng, G., Fully Solar-Powered Photoelectrochemical Conversion for Simultaneous Energy Storage and Chemical Sensing. Nano Lett. 2014, 14, 3668.

24. Dunn, H. K.; Feckl, J. M.; Muller, A.; Fattakhova-Rohlfing, D.; Morehead, S. G.; Roos, J.; Peter, L. M.; Scheu, C.; Bein, T., Tin doping speeds up hole transfer during light-driven water oxidation at hematite photoanodes. Phys. Chem. Chem. Phys. 2014, 16, 24610.

25. Tarascon, J. M.; Armand, M., Issues and challenges facing rechargeable lithium batteries. Nature 2001, 414, 359.

26. Rolison, D. R.; Long, J. W.; Lytle, J. C.; Fischer, A. E.; Rhodes, C. P.; McEvoy, T. M.; Bourg, M. E.; Lubers, A. M., Multifunctional 3D nanoarchitectures for energy storage and conversion. Chem. Soc. Rev. 2009, 38, 226.

27. Rauda, I. E.; Augustyn, V.; SaldarriagaLopez, L. C.; Chen, X.; Schelhas, L. T.; Rubloff, G. W.; Dunn, B.; Tolbert, S. H., Nanostructured Pseudocapacitors Based on Atomic Layer Deposition of V2O5 onto Conductive Nanocrystal-based Mesoporous ITO Scaffolds. Adv. Funct. Mater. 2014, 24, 6717.

28. Coustier, F.; Hill, J.; Owens, B. B.; Passerini, S.; Smyrl, W. H., Doped Vanadium Oxides as Host Materials for Lithium Intercalation. J. Electrochem. Soc. 1999, 146, 1355.

29. Stefik, M.; Cornuz, M.; Mathews, N.; Hisatomi, T.; Mhaisalkar, S.; Grätzel, M., Transparent, Conducting $\mathrm{Nb}: \mathrm{SnO} 2$ for Host-Guest Photoelectrochemistry. Nano Lett. 2012, 12, 5431.

30. Velev, O. D.; Kaler, E. W., Structured Porous Materials via Colloidal Crystal Templating: From Inorganic Oxides to Metals. Adv. Mater. 2000, 12, 531.

31. Kulinowski, K. M.; Jiang, P.; Vaswani, H.; Colvin, V. L., Porous Metals from Colloidal Templates. Adv. Mater. 2000, 12, 833.

32. Yi, G.-R.; Moon, J. H.; Yang, S.-M., Ordered Macroporous Particles by Colloidal Templating. Chem. Mater. 2001, 13, 2613.

33. Phillips, K. R.; England, G. T.; Sunny, S.; Shirman, E.; Shirman, T.; Vogel, N.; Aizenberg, J., A colloidoscope of colloidbased porous materials and their uses. Chem. Soc. Rev. 2015.

34. Rouquerol, J.; Avnir, D.; Fairbridge, C. W.; Everett, D. H.; Haynes, J. M.; Pernicone, N.; Ramsay, J. D. F.; Sing, K. S. W.; Unger, K. K., Recommendations for the 
characterization of porous solids (Technical Report). In Pure Appl. Chem., 1994; Vol. 66, p 1739.

35. Sing, K. S. W., Reporting physisorption data for gas/solid systems with special reference to the determination of surface area and porosity (Recommendations 1984). In Pure Appl. Chem., 1985; Vol. 57, p 603.

36. Okubo, M.; Hosono, E.; Kim, J.; Enomoto, M.; Kojima, N.; Kudo, T.; Zhou, H.; Honma, I., Nanosize Effect on High-Rate Li-Ion Intercalation in $\mathrm{LiCoO} 2$ Electrode. $J$. Am. Chem. Soc. 2007, 129, 7444.

37. Beck, J. S.; Vartuli, J. C.; Roth, W. J.; Leonowicz, M. E.; Kresge, C. T.; Schmitt, K. D.; Chu, C. T. W.; Olson, D. H.; Sheppard, E. W., A new family of mesoporous molecular sieves prepared with liquid crystal templates. J. Am. Chem. Soc. 1992, 114, 10834.

38. Schmidt-Winkel, P.; Lukens, W. W.; Yang, P.; Margolese, D. I.; Lettow, J. S.; Ying, J. Y.; Stucky, G. D., Microemulsion Templating of Siliceous Mesostructured Cellular Foams with Well-Defined Ultralarge Mesopores. Chem. Mater. 2000, 12, 686 .

39. Kimura, T.; Itoh, D.; Shigeno, T.; Kuroda, K., Silica-Based Mesostructured Materials Induced by Surfactant Assemblies in the Two-Dimensionally Limited Space of a Layered Polysilicate Kanemite. Bull. Chem. Soc. Jpn. 2004, 77, 585.

40. Templin, M.; Franck, A.; Du Chesne, A.; Leist, H.; Zhang, Y.; Ulrich, R.; Schädler, V.; Wiesner, U., Organically Modified Aluminosilicate Mesostructures from Block Copolymer Phases. Science 1997, 278, 1795.

41. Zhao, D.; Feng, J.; Huo, Q.; Melosh, N.; Fredrickson, G. H.; Chmelka, B. F.; Stucky, G. D., Triblock Copolymer Syntheses of Mesoporous Silica with Periodic 50 to 300 Angstrom Pores. Science 1998, 279, 548.

42. Memesa, M.; Lenz, S.; Emmerling, S. G. J.; Nett, S.; Perlich, J.; Müller-Buschbaum, P.; Gutmann, J. S., Morphology and photoluminescence study of titania nanoparticles. Colloid Polym. Sci. 2011, 289, 943.

43. Cheng, Y.-J.; Zhou, S.; Wolkenhauer, M.; Bumbu, G.-G.; Lenz, S.; Memesa, M.; Nett, S.; Emmerling, S.; Steffen, W.; Gutmann, J. S., Morphology Evolution in Mesoporous Titania Block Copolymer Composite Films with Increasing Sol-Gel Reaction Time. Eur. J. Inorg. Chem. 2013, 2013, 1127.

44. Cheng, Y.-J.; Gutmann, J. S., Morphology Phase Diagram of Ultrathin Anatase $\mathrm{TiO} 2$ Films Templated by a Single PS-b-PEO Block Copolymer. J. Am. Chem. Soc. 2006, $128,4658$.

45. Alberius, P. C. A.; Frindell, K. L.; Hayward, R. C.; Kramer, E. J.; Stucky, G. D.; Chmelka, B. F., General Predictive Syntheses of Cubic, Hexagonal, and Lamellar Silica and Titania Mesostructured Thin Films $\S$. Chem. Mater. 2002, 14, 3284.

46. Deng, Y.; Yu, T.; Wan, Y.; Shi, Y.; Meng, Y.; Gu, D.; Zhang, L.; Huang, Y.; Liu, C.; Wu, X.; Zhao, D., Ordered Mesoporous Silicas and Carbons with Large Accessible Pores Templated from Amphiphilic Diblock Copolymer Poly(ethylene oxide)-bpolystyrene. J. Am. Chem. Soc. 2007, 129, 1690.

47. Yu, K.; Hurd, A. J.; Eisenberg, A.; Brinker, C. J., Syntheses of Silica/Polystyreneblock-Poly(ethylene oxide) Films with Regular and Reverse Mesostructures of Large Characteristic Length Scales by Solvent Evaporation-Induced SelfAssembly. Langmuir 2001, 17, 7961.

48. Smarsly, B.; Xomeritakis, G.; Yu, K.; Liu, N.; Fan, H.; Assink, R. A.; Drewien, C. A.; Ruland, W.; Brinker, C. J., Microstructural Characterization of Polystyrene-blockpoly(ethylene oxide)-Templated Silica Films with Cubic-Ordered Spherical Mesopores. Langmuir 2003, 19, 7295.

49. Yu, K.; Smarsly, B.; Brinker, C. J., SelfAssembly and Characterization of Mesostructured Silica Films with a 3D Arrangement of Isolated Spherical Mesopores. Adv. Funct. Mater. 2003, 13, 47. 
50. Kruk, M.; Dufour, B.; Celer, E. B.; Kowalewski, T.; Jaroniec, M.; Matyjaszewski, K., Well-Defined Poly(ethylene oxide)-Polyacrylonitrile Diblock Copolymers as Templates for Mesoporous Silicas and Precursors for Mesoporous Carbons. Chem. Mater. 2006, 18, 1417.

51. Stefik, M.; Lee, J.; Wiesner, U., Nanostructured carbon-crystalline titania composites from microphase separation of poly(ethylene oxide-b-acrylonitrile) and titania sols. Chem. Commun. 2009, 2532.

52. Cheng, Y.-J.; Müller-Buschbaum, P.; Gutmann, J. S., Ultrathin Anatase TiO2 Films with Stable Vesicle Morphology Templated by PMMA-b-PEO. Small 2007, 3,1379 .

53. Wei, J.; Li, Y.; Wang, M.; Yue, Q.; Sun, Z.; Wang, C.; Zhao, Y.; Deng, Y.; Zhao, D., A systematic investigation of the formation of ordered mesoporous silicas using poly(ethylene oxide)-b-poly(methyl methacrylate) as the template. J. Mater. Chem.A 2013, 1, 8819.

54. Wei, J.; Deng, Y.; Zhang, J.; Sun, Z.; Tu, B.; Zhao, D., Large-pore ordered mesoporous carbons with tunable structures and pore sizes templated from poly(ethylene oxide)-b-poly(methyl methacrylate). Solid State Sciences 2011, 13,784 .

55. Groenewolt, M.; Brezesinski, T.; Schlaad, H.; Antonietti, M.; Groh, P. W.; Iván, B., Polyisobutylene-block-Poly(ethylene oxide) for Robust Templating of Highly Ordered Mesoporous Materials. Adv. Mater. 2005, 17, 1158.

56. Thomas, A.; Schlaad, H.; Smarsly, B.; Antonietti, M., Replication of Lyotropic Block Copolymer Mesophases into Porous Silica by Nanocasting: Learning about Finer Details of Polymer Self-Assembly. Langmuir 2003, 19, 4455.

57. Brezesinski, T.; Wang, J.; Polleux, J.; Dunn, B.; Tolbert, S. H., Templated Nanocrystal-Based Porous TiO2 Films for Next-Generation Electrochemical
Capacitors. J. Am. Chem. Soc. 2009, 131, 1802.

58. Wang, Y.; Brezesinski, T.; Antonietti, M.; Smarsly, B., Ordered Mesoporous Sb-, Nb-, and Ta-Doped $\mathrm{SnO} 2$ Thin Films with Adjustable Doping Levels and High Electrical Conductivity. ACS Nano 2009, 3, 1373

59. Brezesinski, T.; Fischer, A.; Iimura, K. i.; Sanchez, C.; Grosso, D.; Antonietti, M.; Smarsly, B. M., Generation of SelfAssembled 3D Mesostructured SnO2 Thin Films with Highly Crystalline Frameworks. Adv. Funct. Mater. 2006, 16, 1433.

60. Brezesinski, K.; Haetge, J.; Wang, J.; Mascotto, S.; Reitz, C.; Rein, A.; Tolbert, S. H.; Perlich, J.; Dunn, B.; Brezesinski, T., Ordered Mesoporous $\alpha$-Fe2O3 (Hematite) Thin-Film Electrodes for Application in High Rate Rechargeable Lithium Batteries. Small 2011, 7, 407.

61. Rauda, I. E.; Buonsanti, R.; SaldarriagaLopez, L. C.; Benjauthrit, K.; Schelhas, L. T.; Stefik, M.; Augustyn, V.; Ko, J.; Dunn, B.; Wiesner, U.; Milliron, D. J.; Tolbert, S. H., General Method for the Synthesis of Hierarchical Nanocrystal-Based Mesoporous Materials. ACS Nano 2012, 6, 6386.

62. Stefik, M.; Wang, S.; Hovden, R.; Sai, H.; Tate, M. W.; Muller, D. A.; Steiner, U.; Gruner, S. M.; Wiesner, U., Networked and chiral nanocomposites from $\mathrm{ABC}$ triblock terpolymer coassembly with transition metal oxide nanoparticles. J. Mater. Chem. 2012, 22, 1078.

63. Docampo, P.; Stefik, M.; Guldin, S.; Gunning, R.; Yufa, N. A.; Cai, N.; Wang, P.; Steiner, U.; Wiesner, U.; Snaith, H. J., Triblock-Terpolymer-Directed SelfAssembly of Mesoporous TiO2: HighPerformance Photoanodes for Solid-State Dye-Sensitized Solar Cells. Adv. Energy Mater. 2012, 2, 676.

64. Hoheisel, T. N.; Hur, K.; Wiesner, U. B., Block copolymer-nanoparticle hybrid selfassembly. Prog. Polym. Sci. 2015, 40, 3.

65. Cheng, Y.-J.; Zhi, L.; Steffen, W.; Gutmann, J. S., Surface-Supported, Highly 
Ordered Macroporous Crystalline $\mathrm{TiO} 2$ Thin Films Robust up to $1000{ }^{\circ} \mathrm{C}$. Chem. Mater. 2008, 20, 6580.

66. Garcia, B. C.; Kamperman, M.; Ulrich, R.; Jain, A.; Gruner, S. M.; Wiesner, U., Morphology Diagram of a Diblock Copolymer-Aluminosilicate Nanoparticle System. Chem. Mater. 2009, 21, 5397.

67. Ortel, E.; Fischer, A.; Chuenchom, L.; Polte, J.; Emmerling, F.; Smarsly, B.; Kraehnert, R., New Triblock Copolymer Templates, PEO-PB-PEO, for the Synthesis of Titania Films with Controlled Mesopore Size, Wall Thickness, and Bimodal Porosity. Small 2012, 8, 298.

68. Haliloğlu, T.; Bahar, I.; Erman, B.; Mattice, W. L., Mechanisms of the Exchange of Diblock Copolymers between Micelles at Dynamic Equilibrium. Macromolecules 1996, 29, 4764.

69. Halperin, A.; Alexander, S., Polymeric micelles: their relaxation kinetics. Macromolecules 1989, 22, 2403.

70. Dormidontova, E. E., Micellization Kinetics in Block Copolymer Solutions: Scaling Model. Macromolecules 1999, 32, 7630.

71. Denkova, A. G.; Mendes, E.; Coppens, M.O., Non-equilibrium dynamics of block copolymer micelles in solution: recent insights and open questions. Soft Matter 2010, 6, 2351.

72. Hayward, R. C.; Pochan, D. J., Tailored Assemblies of Block Copolymers in Solution: It Is All about the Process. Macromolecules 2010, 43, 3577.

73. Leibler, L., Theory of Microphase Separation in Block Copolymers. Macromolecules 1980, 13, 1602.

74. Hiorns, R., Polymer Handbook, 4th edn, Edited by J Brandup, EH Immergut and EA Grulke, Associate Editors A Abe and DR Bloch, John Wiley and Sons, New York, 1999, pp 2250, price £210 ISBN 0-47116628-6. Polym. Int. 2000, 49, 807.

75. Stefik, M.; Mahajan, S.; Sai, H.; Epps, T. H.; Bates, F. S.; Gruner, S. M.; DiSalvo, F. J.; Wiesner, U., Ordered Three- and Fiveply Nanocomposites from ABC Block Terpolymer Microphase Separation with
Niobia and Aluminosilicate Sols. Chem. Mater. 2009, 21, 5466.

76. Baklanov, M. R.; Mogilnikov, K. P.; Polovinkin, V. G.; Dultsev, F. N., Determination of pore size distribution in thin films by ellipsometric porosimetry. $J$. Vac. Sci. \& Technol., B 2000, 18, 1385.

77. Bourgeois, A.; Turcant, Y.; Walsh, C.; Defranoux, C., Ellipsometry porosimetry (EP): Thin film porosimetry by coupling an adsorption setting with an optical measurement, highlights on diffusion results. Appl. Surf. Sci. 2009, 256, S26.

78. Boissiere, C.; Grosso, D.; Lepoutre, S.; Nicole, L.; Bruneau, A. B.; Sanchez, C., Porosity and Mechanical Properties of Mesoporous Thin Films Assessed by Environmental Ellipsometric Porosimetry. Langmuir 2005, 21, 12362.

79. Simon, P. F. W.; Ulrich, R.; Spiess, H. W.; Wiesner, U., Block Copolymer-Ceramic Hybrid Materials from Organically Modified Ceramic Precursors. Chem. Mater. 2001, 13, 3464.

80. Stefik, M.; Song, J.; Sai, H.; Guldin, S.; Boldrighini, P.; Orilall, M. C.; Steiner, U.; Gruner, S. M.; Wiesner, U., Ordered mesoporous titania from highly amphiphilic block copolymers: tuned solution conditions enable highly ordered morphologies and ultra-large mesopores. $J$. Mater. Chem.A 2015, 3, 11478.

81. Kelley, E. G.; Murphy, R. P.; Seppala, J. E.; Smart, T. P.; Hann, S. D.; Sullivan, M. O.; Epps, T. H., Size evolution of highly amphiphilic macromolecular solution assemblies via a distinct bimodal pathway. Nat Commun 2014, 5.

82. Kelley, E. G.; Smart, T. P.; Jackson, A. J.; Sullivan, M. O.; Epps, T. H., Structural changes in block copolymer micelles induced by cosolvent mixtures. Soft Matter 2011, 7, 7094.

83. Luo, L.; Eisenberg, A., Thermodynamic Size Control of Block Copolymer Vesicles in Solution. Langmuir 2001, 17, 6804.

84. Horn, M.; Matyjaszewski, K., Solvent Effects on the Activation Rate Constant in 
Atom Transfer Radical Polymerization. Macromolecules 2013, 46, 3350.

85. Creutz, S.; van Stam, J.; Antoun, S.; De Schryver, F. C.; Jérôme, R., Exchange of Polymer Molecules between Block Copolymer Micelles Studied by Emission Spectroscopy. A Method for the Quantification of Unimer Exchange Rates. Macromolecules 1997, 30, 4078.

86. Creutz, S.; van Stam, J.; De Schryver, F. C.; Jérôme, R., Dynamics of Poly((dimethylamino)alkyl methacrylateblock-sodium methacrylate) Micelles. Influence of Hydrophobicity and Molecular Architecture on the Exchange Rate of Copolymer Molecules. Macromolecules 1998, 31, 681 .

87. Mori, K.; Hasegawa, H.; Hashimoto, T., Small-Angle X-Ray Scattering from Bulk Block Polymers in Disordered State. Estimation of [chi]-Values from Accidental Thermal Fluctuations. Polym. J. 1985, 17, 799.

88. Sinturel, C.; Bates, F. S.; Hillmyer, M. A., High $\chi$-Low N Block Polymers: How Far Can We Go? ACS Macro Letters 2015, 4, 1044.

89. Connell, J. G.; Richards, R. W., Application of the random phase approximation to styrene-isoprene diblock copolymers in solution. Macromolecules 1990, 23, 1766.

90. Kim, J. K.; Kimishima, K.; Hashimoto, T., Random-phase approximation calculation of the scattering function for multicomponent polymer systems. Macromolecules 1993, 26, 125.

91. Cochran, E. W.; Morse, D. C.; Bates, F. S., Design of ABC Triblock Copolymers near the ODT with the Random Phase Approximation. Macromolecules 2003, 36, 782.

92. Floudas, G.; Ulrich, R.; Wiesner, U., Microphase separation in poly(isoprene-bethylene oxide) diblock copolymer melts. I. Phase state and kinetics of the order-toorder transitions. J. Chem. Phys. 1999, $110,652$.

93. Bates, F. S.; Fredrickson, G. H., Block Copolymer Thermodynamics: Theory and
Experiment. Annu. Rev. Phys. Chem. 1990, 41, 525.

94. Bates, F. S.; Schulz, M. F.; Khandpur, A. K.; Forster, S.; Rosedale, J. H.; Almdal, K.; Mortensen, K., Fluctuations, conformational asymmetry and block copolymer phase behaviour. Faraday Discuss. 1994, 98, 7.

95. Hamley, I. W.; Castelletto, V.; Yang, Z.; Price, C.; Booth, C., Melt Phase Behavior of Poly(oxyethylene)-Poly(oxypropylene) Diblock Copolymers. Macromolecules 2001, 34, 4079.

96. Choi, S.-H.; Lodge, T. P.; Bates, F. S., Mechanism of Molecular Exchange in Diblock Copolymer Micelles: Hypersensitivity to Core Chain Length. Phys. Rev. Lett. 2010, 104, 047802.

97. Won, Y.-Y.; Davis, H. T.; Bates, F. S., Molecular Exchange in PEO-PB Micelles in Water. Macromolecules 2003, 36, 953.

98. Steunou, N.; Forster, S.; Florian, P.; Sanchez, C.; Antonietti, M., Synthesis of nanostructured polymer-titanium oxide composites through the assembly of titanium-oxo clusters and amphiphilic block copolymers micelles. J. Mater. Chem. 2002, 12, 3426.

99. Murphy, R. P.; Kelley, E. G.; Rogers, S. A.; Sullivan, M. O.; Epps, T. H., Unlocking Chain Exchange in Highly Amphiphilic Block Polymer Micellar Systems: Influence of Agitation. ACS Macro Letters 2014, 3, 1106.

100. Stefik, M.; Sai, H.; Sauer, K.; Gruner, S. M.; DiSalvo, F. J.; Wiesner, U., ThreeComponent Porous-Carbon-Titania Nanocomposites through Self-Assembly of ABCBA Block Terpolymers with Titania Sols. Macromolecules 2009, 42, 6682.

101. Guldin, S.; Stefik, M.; Sai, H.; Wiesner, U.; Steiner, U., Controlling the coassembly of highly amphiphilic block copolymers with a hydrolytic sol by solvent exchange. RSC Advances 2015, 5, 22499.

102. Yang, P.; Zhao, D.; Margolese, D. I.; Chmelka, B. F.; Stucky, G. D., Generalized syntheses of large-pore mesoporous metal 
oxides with semicrystalline frameworks. Nature 1998, 396, 152.

103. Choi, S. Y.; Mamak, M.; Coombs, N.; Chopra, N.; Ozin, G. A., Thermally Stable Two-Dimensional Hexagonal Mesoporous Nanocrystalline Anatase, Meso-nc-TiO2: Bulk and Crack-Free Thin Film Morphologies. Adv. Funct. Mater. 2004, 14, 335.

104. Ruland, W.; Smarsly, B. M., Twodimensional small-angle X-ray scattering of self-assembled nanocomposite films with oriented arrays of spheres: determination of lattice type, preferred orientation, deformation and imperfection. J. Appl. Crystallogr. 2007, 40, 409.

105. Soler-Illia, G. J. d. A. A.; Sanchez, C., Interactions between poly(ethylene oxide)based surfactants and transition metal alkoxides: their role in the templated construction of mesostructured hybrid organic-inorganic composites. New J. Chem. 2000, 24, 493.

106. Toombes, G. E. S.; Finnefrock, A. C.; Tate, M. W.; Ulrich, R.; Wiesner, U.; Gruner, S. M., A Re-Evaluation of the Morphology of a Bicontinuous Block Copolymer-Ceramic Material. Macromolecules 2007, 40, 8974.

107. Schuster, J.; Köhn, R.; Keilbach, A.; Döblinger, M.; Amenitsch, H.; Bein, T., Two-Dimensional-Hexagonal Periodic Mesoporous Polymer Resin Thin Films by Soft Templating. Chem. Mater. 2009, 21, 5754.

108. Hexemer, A.; Müller-Buschbaum, P., Advanced grazing-incidence techniques for modern soft-matter materials analysis. IUCrJ 2015, 2, 106.

109. Paul, N.; Brumbarov, J.; Paul, A.; Chen, Y.; Moulin, J.-F.; Muller-Buschbaum, P.; Kunze-Liebhauser, J.; Gilles, R., GISAXS and TOF-GISANS studies on surface and depth morphology of self-organized $\mathrm{TiO} 2$ nanotube arrays: model anode material in Li-ion batteries. J. Appl. Crystallogr. 2015, $48,444$.

110. Smarsly, B.; Antonietti, M., Block Copolymer Assemblies as Templates for the Generation of Mesoporous Inorganic Materials and Crystalline Films. Eur. J. Inorg. Chem. 2006, 2006, 1111.

111. Wang, X.; Dormidontova, E. E.; Lodge, T. P., The Order-Disorder Transition and the Disordered Micelle Regime for Poly(ethylenepropylene-b-

dimethylsiloxane)

Macromolecules 2002, 35, 9687.

112. Dutta, S.; Wu, K. C. W.; Kimura, T., Predictable Shrinkage during the Precise Design of Porous Materials and Nanomaterials. Chem. Mater. 2015, 27, 6918.

113. Kimura, T.; Yamauchi, Y.; Miyamoto, N., Condensation- and Crystallinity-Controlled Synthesis of Titanium Oxide Films with Assessed Mesopores. Chem. Eur. J. 2010, 16, 12069.

114. Sing, K. S. W.; Everett, D. H.; Haul, R. A. W.; Moscou, L.; Pierotti, R. A.; Rouquerol, J.; Siemieniewska, T., Reporting Physisorption Data for Gas/Solid Systems. In Handbook of Heterogeneous Catalysis, Wiley-VCH Verlag GmbH \& Co. KGaA: 2008

115. Zhulina, E. B.; Adam, M.; LaRue, I.; Sheiko, S. S.; Rubinstein, M., Diblock Copolymer Micelles in a Dilute Solution. Macromolecules 2005, 38, 5330.

116. Lund, R.; Willner, L.; Richter, D., Kinetics of Block Copolymer Micelles Studied by Small-Angle Scattering Methods. In Controlled Polymerization and Polymeric Structures, Abe, A.; Lee, K.-S.; Leibler, L.; Kobayashi, S., Eds. Springer International Publishing: 2013; Vol. 259, pp 51-158. 